\title{
Questões emergentes na análise demográfica: o caso brasileiro*
}

\author{
Eduardo Luiz Gonçalvez Rios-Neto*
}

\begin{abstract}
Este artigo levanta questões emergentes para a análise demográfica brasileira. O trabalho começa com uma análise dos três componentes da dinâmica demográfica, enfatizando a questão sobre o declínio da fecundidade e a possibilidade de a mesma atingir níveis abaixo da reposição. As tendências futuras de emigração internacional também são discutidas. Passando para as conseqüências demográficas desta dinâmica, o texto aborda, ainda, a demografia dos efeitos de composição, ressaltando as conseqüências demográficas do diferencial de fecundidade por educação materna e mostrando que a dinâmica de melhoria educacional das mães mais que compensa este diferencial. $O$ dividendo demográfico é discutido tanto conceitualmente quanto empiricamente, ficando indicada uma agenda para estudos futuros. Finalmente, uma discussão mais conceitual sobre transferências intergeracionais tenta colocar o debate na perspectiva do gasto público brasileiro, enfatizando trabalhos relevantes que começam a ser desenvolvidos.
\end{abstract}

Palavras-chave: Fecundidade abaixo da reposição. Dividendo demográfico. Transferências intergeracionais. Educação. Seguridade social.

\section{Introdução}

O objetivo deste artigo é levantar questões emergentes para a análise demográfica, considerando tanto seu interesse analítico quanto suas implicações de políticas públicas para o caso brasileiro. Dois alertas devem ser imediatamente explicitados. Em primeiro lugar, a escolha das questões emergentes reflete as preferências temáticas, assim como a formação do autor. Portanto, por maior que seja a abrangência pretendida neste ensaio, as abordagens serão sempre condicionadas às possibilidades do autor. Em segundo lugar, o tratamento das questões obedece a um certo nível de superficialidade, uma vez que há um limite de espaço e vários dos temas contemplados são independentes.

A primeira parte deste ensaio faz uma breve menção sobre a dinâmica demográfica brasileira recente, no que tange aos seus componentes, enfatizando as principais incertezas futuras em cenários de projeções, e às implicações para a estrutura etária da população futura. A dinâmica demográfica futura, principalmente no que diz respeito à estrutura etária, introduz o debate das implicações no nível macro. A segunda parte trata deste nível macro, em

\footnotetext{
* O autor gostaria de creditar o apoio recebido como bolsista de produtividade do CNPq, Conselho Nacional de Desenvolvimento Científico e Tecnológico. Agradeço também o apoio das pesquisadoras Juliana Ruas Riani e Vânia Cristina Liberato.

** Professor titular do Departamento de Demografia e do Cedeplar, UFMG.
} 
que três temas serão abordados: a demografia dos efeitos de composição; o dividendo demográfico e seu debate; e as transferências intergeracionais. A terceira parte, à guisa de conclusão, menciona a relação dos temas anteriormente discutidos com tópicos igualmente relevantes, mas que ficaram fora da discussão por falta de espaço, constituindo-se, também, em agenda para estudos futuros.

\section{A dinâmica demográfica brasileira e a estrutura etária}

A dinâmica demográfica brasileira será brevemente revisada aqui, a partir da análise da fecundidade, da mortalidade e da migração - mais especificamente, da migração internacional. A discussão acerca destes componentes estará mais focada nos desafios futuros do que numa descrição detalhada das tendências e seus determinantes, amplamente conhecidos pelos demógrafos brasileiros.

\section{Fecundidade}

O componente demográfico mais importante, em termos das implicações futuras imediatas na estrutura etária da população brasileira, é, sem dúvida, a fecundidade, considerada tanto em termos da sua trajetória passada quanto da sua tendência nas próximas décadas. A fecundidade passada causa impacto nas flutuações da estrutura etária, associandose à chamada inércia populacional, enquanto a fecundidade futura determina as mudanças mais imediatas na base da pirâmide, ou seja, na participação dos grupos etários mais jovens.

O Brasil chegou ao final do século XX tendo praticamente completado a chamada transição da fecundidade. A Taxa de Fecundidade Total (TFT), definida como o número total de filhos que uma mulher teria ao final do período reprodutivo, passou de 6,3 filhos por mulher, em 1960, para 2,9 em 1991 e diminuiu para 2,3 em 2000. Os resultados da PNAD de 2003 apontam uma taxa de fecundidade total de 2,1 filhos por mulher, o que representa o chamado nível de reposição. Isto quer dizer que, se esta taxa perdurar por um período de cerca de 25 anos, o crescimento populacional brasileiro convergirá para zero. O ponto mais relevante é que não há evidências claras de que a taxa de fecundidade total brasileira pararia em 2,1 filhos por mulher, fazendo com que se espere um padrão de fecundidade brasileira abaixo do nível de reposição nas primeiras décadas do século $X X I$, um resultado que poderá seguir aquele encontrado em países europeus, principalmente Espanha, Portugal, Itália e Grécia. Foge aos propósitos deste artigo discutir as causas deste rápido declínio da fecundidade, cabendo abordar as possibilidades de estabilização ou não da fecundidade no nível de reposição.

Dois pontos característicos da fecundidade brasileira corrente merecem destaque e foram discutidos por Berquó e Cavenaghi (2004): o rejuvenescimento da fecundidade brasileira; e os segmentos de pobreza com alta fecundidade. O primeiro ponto será discutido aqui e o segundo ao final deste item.

$O$ rejuvenescimento da fecundidade brasileira é mostrado pelo fato de as taxas específicas de fecundidade de todos os grupos etários terem diminuído entre 1980 e 2000, exceto no grupo de mulheres de 15 a 19 anos. Além disso, a redução é mais pronunciada entre a mulheres de 25 a 44 anos. Já o grupo de 15 a 19 anos representava $9,2 \%$ da taxa de fecundidade total, em 1980, passando para 13,9\%, em 1991, e para $19,9 \%$, em 2000 . Isto quer dizer que cerca $20 \%$ da fecundidade total de 2000 é gerada por mães adolescentes, unidas ou não.

Uma grave conseqüência desta situação é que, mantendo-se tudo o mais constante, uma política de informação e provisão de serviços de planejamento familiar que possa favorecer a postergação da maternidade e da união, perfeitamente compatível com políticas universais de combate à pobreza e com os cânones de políticas de saúde reprodutiva da mulher, tem grandes chances de favorecer um maior declínio da taxa de fecundidade. $\mathrm{O}$ corolário seria uma queda desta taxa em 
níveis abaixo da reposição. Caso isto ocorra, será um claro problema de externalidade negativa, na acepção econômica do termo, que decorre do fato de que um comportamento de adiamento da união e da primeira gravidez, por parte das mulheres jovens, aumentaria seu bem-estar no nível micro, ao mesmo tempo em que agravaria potencialmente o contexto macro, ao causar redução exagerada da população jovem brasileira no futuro imediato. Como sempre ocorre nos problemas de externalidade, não se trata de tentar manter a fecundidade das jovens brasileiras no patamar corrente, para se evitar uma grande queda da fecundidade abaixo da reposição. Há que se pensar em estratégias alternativas de longuíssimo prazo. Este é um dos problemas mais complexos que desafiam a análise e a formulação de políticas no Brasil.

Esse debate indica que já é totalmente pertinente discutir a relação entre o quantum e o tempo da fecundidade brasileira, em uma perspectiva temporal. O quantum da fecundidade é dado pelo número de filhos da coorte sintética, independente do espaçamento e do efeito de composição por parturição. O tempo da fecundidade reflete o impacto do espaçamento decorrente da mudança na idade das progressões por parturição, sem afetar o seu quantum.

Os dados convencionais apontam rejuvenescimento da fecundidade, o que seria indicativo de um efeito tempo negativo - precisamente o contrário do encontrado na literatura européia sobre fecundidade abaixo do nível de reposição. Em outras palavras, uma correção do efeito tempo levaria a um índice de quantum abaixo da TFT observada, enquanto, na Europa, o que se observa é um efeito tempo positivo, que reduz a fecundidade, sugerindo um índice de quantum acima da TFT observada. A grande dificuldade de cálculo destes índices, para o Brasil, decorre da ausência de histórias de nascimento confiáveis, principalmente num longo período, em- bora as mesmas estivessem disponíveis nas pesquisas DHS-Bemfam de 1986 e 1996.

Um trabalho pioneiro que trata do tema, digno de menção, é o de Berquó (1980), publicado nos Anais do II Encontro Nacional de Estudos Populacionais da Abep. A autora baseia-se na formulação pioneira de Norman Ryder e nos trabalhos técnicos de German Rodriguez e John Hobcraft, no contexto do World Fertility Survey, para conduzir sua análise da Pesquisa Nacional de Reprodução Humana, do Cebrap. A tábua de fecundidade estimada por Berquó é um instrumento muito parecido com a estimativa do índice puro de fecundidade, construído a partir da progressão por parturição. A tábua permite, também, a estimativa da idade média na transição de cada parturição. Atualmente, há um grupo no Cedeplar ${ }^{1}$ que está desenvolvendo um método para gerar histórias de nascimento a partir da estrutura domiciliar dos censos demográficos. Uma primeira tentativa de aplicação do método foi apresentada na Conferência da International Union for Scientific Study of Population (lussp), em Tours (Silva; Miranda-Ribeiro; Rios-Neto, 2005).

Os resultados ainda não são plenamente confiáveis, uma vez que o mecanismo de reconstrução da história de nascimentos pode ser bastante melhorado. De qualquer forma, os resultados preliminares mostraram que dois efeitos fazem com que a TFT observada no Brasil seja maior do que o índice puro de fecundidade (quantum). Em primeiro lugar, o efeito tempo é negativo, embora nas estimativas seja inferior a 10\%. Em segundo lugar, há um forte efeito positivo de composição por parturição, ou seja, a mudança na composição por parturição, ao longo do tempo, favorece um efeito de composição na TFT, que a coloca em níveis de fecundidade mais altos do que aqueles que serão observados no índice puro de fecundidade. Este efeito é substancial - em torno de $30 \%$. É possível

\footnotetext{
${ }^{1}$ Eduardo Rios-Neto, José Alberto Magno de Carvalho, Adriana Miranda-Ribeiro, Vânia Candida da Silva e José Antonio Ortega, este último professor da Universidad Salamanca, na Espanha.
} 
que a aplicação do algoritmo de KohlerOrtega, que corrige o efeito tempo através da incorporação de um componente de variância na curva de fecundidade, esteja reduzindo o efeito tempo (em termos absolutos) e aumentando o efeito parturição. De qualquer forma, este primeiro exercício mostra que o índice puro de fecundidade (quantum) já estava abaixo dos níveis de reposição em 1987, quando encontrava-se em 2 filhos por mulher, tendo diminuído para 1,7 em 2000. Estes resultados devem ser considerados com reserva, uma vez que serão replicados com melhores reconstruções das histórias de nascimentos e variações nos algoritmos de cálculo dos efeitos tempo, parturição e do índice puro de fecundidade.

Um corte destes efeitos para grupos de mulheres, divididos em três níveis de escolaridade (0 a 3 anos de estudo, 4 a 8 e 9 ou mais), indica, para 2000, um índice puro de fecundidade praticamente igual em torno de 2 filhos - para os dois primeiros grupos, caindo para 1,4 naquele composto por mulheres com 9 ou mais anos de estudo. Isto quer dizer que o diferencial de TFT observado entre os três grupos $(3,3$; 2,6 e 1,6, respectivamente) deve-se conjuntamente aos efeitos tempo negativo e parturição positivo. Estas distorções entre a TFT e o índice puro são bem menores no caso das mulheres mais escolarizadas. Tal fato reflete, provavelmente, diferenças quanto ao momento em que o declínio no quantum e a mudança na estrutura ocorreram no tempo.

Estes resultados, associados ao índice puro de fecundidade, parecem ser consistentes com a taxa de fecundidade total desejada. Os dois conceitos, embora sejam calculados em bases totalmente distintas, parecem captar um efeito similar, ou seja, o quantum da fecundidade. De fato, com base na pesquisa DHS-Bemfam de 1996, Wong (1998) calculou a taxa de fecundidade total, a desejada e a indesejada, para o Brasil: 2,42, 1,64 e 0,79, respectivamente. MirandaRibeiro (2004) calculou as duas primeiras taxas para Belo Horizonte e Recife, baseando-se no survey SRSR, ${ }^{2}$ realizado em 2002. A TFT girava em torno de 1,8 filho nas duas capitais, sendo que a TFT desejada era de 1,44 em Belo Horizonte e 1,36 em Recife. Controlando-se pela escolaridade da mãe, a TFT desejada só ficou acima do nível de reposição entre as mulheres com 0 a 4 anos de estudo em Belo Horizonte (2,23 filhos). Em todos os outros casos, ela estava bem abaixo do nível de reposição.

Voltando aos resultados de Silva, Miranda-Ribeiro e Rios-Neto (2005), verifica-se uma menor diferença nas idades médias à parturição das mulheres com baixa e média escolaridade, diferença que se acentua para o caso das mulheres com alta escolaridade (9 anos ou mais de estudo). Se estes resultados forem confirmados com histórias de nascimento mais bem corrigidas, isto indicaria uma diferença de pouco mais de cinco anos entre o grupo de mulheres com menor escolaridade $(0$ a 3 anos de estudo) e aquele com maior escolaridade. No caso da confirmação dos diferenciais acima, uma transição para o efeito tempo positivo fatalmente ocorrerá quando houver um substancial aumento na prevalência de mulheres com maior escolaridade na população. Este seria um momento de transição para os moldes europeus da fecundidade abaixo do nível de reposição, fato que, no presente momento, é apenas uma possibilidade.

Os dados apresentados por Berquó e Cavenaghi (2004) também são ilustrativos da alta fecundidade nos segmentos de extrema carência. As mulheres sem instrução e aquelas com 1 a 3 anos de estudo apresentam fecundidade total de 4,1 filhos e 3,6 filhos, respectivamente, enquanto as mulheres com 9 anos de estudo ou mais registram TFT abaixo do nível de reposição. Resultado similar é obtido quando se considera o rendimento domiciliar per capita. As mulheres residentes em domicílios com rendimento per capita abaixo de um quarto do salário mínimo apresentam taxa

${ }^{2}$ SRSR - Saúde Reprodutiva, Sexualidade e Raça. 
de fecundidade total de 4,6 filhos, enquanto aquelas em domicílios com renda per capita acima de um salário mínimo já estão com a TFT abaixo do nível de reposição.

Em suma, a despeito da baixa fecundidade total em 2000, os segmentos de extrema pobreza e carência educacional ainda mostram altos níveis de fecundidade. Por causa disso, grande parte da opinião pública ainda considera que a alta fecundidade corrente, fruto da carência de opções efetivas de controle da fecundidade, é a causa fundamental da pobreza e da violência urbana. Este tipo de visão confunde correlação com causalidade. Não há dúvidas de que a presença excessiva de crianças num domicílio reduz sua renda per capita, mas os dois fenômenos são gerados pelo mesmo processo, sendo difícil inferir uma relação de causa e efeito.

A provisão de políticas atenuantes à pobreza, através de programas de transferência de renda, como o Bolsa Família, deve causar impactos neste segmento. Idealmente, estes programas deveriam ser acompanhados pela oferta de informações e serviços contraceptivos, no contexto da atenção à saúde reprodutiva das mulheres. Ao mesmo tempo em que este componente de planejamento familiar, no espírito de Cairo, é altamente desejável, fatalmente o corolário desta política integrada é o aumento cada vez maior do declínio da fecundidade para níveis abaixo do de reposição.

É claro que o efeito da transferência direta de renda pode também gerar um incentivo adverso, indutor do aumento na fecundidade - possibilidade teórica que não pode ser descartada, mas que é pouco plausível, caso haja um aumento na escolaridade dos filhos destas famílias pobres, além da provisão dos serviços de planejamento familiar.

A agenda para os estudos sobre fecundidade consiste em saber quão rápido, e até que nível, a fecundidade cairá abaixo do nível de reposição. No contexto deste debate, cabe discutir as chances de o país passar por uma segunda transição demográfica, com elevação na idade da primeira união e do primeiro filho. Cabe também discutir o ritmo de queda na fecundidade dos segmentos mais pobres e menos escolarizados, inclusive avaliando o impacto dos programas de transferência de renda.

\section{Mortalidade}

A população brasileira experimentou uma queda na mortalidade antes da redução na fecundidade, conforme indica o aumento da esperança de vida ao nascer, que passou de 43,6 anos, na década de 40 , para 53,7 , na de 60 . A mortalidade continuou sua tendência de declínio nos anos 70 , com a esperança de vida passando para 59,9 anos - um ganho de 6,2 anos apenas nesta década. Em 1980, a esperança de vida ao nascer chegou a 62,4 anos (Carvalho, 1988). Estimativas do Atlas Racial Brasileiro (2004) apontam para uma esperança de vida equivalente a 64,7 anos em 1990 e a 68,6 anos em 2000.

De acordo com estudo do IBGE (Tábua de Vida 2001), o diferencial de esperança de vida por sexo vem aumentando, em parte devido ao peso das mortes por causas externas. A esperança de vida das muIheres, em 1980, era de 66 anos, contra 59,6 anos dos homens, ou seja, 6,4 anos a mais para as mulheres. Em 2001, a esperança de vida feminina já era 7,8 anos superior à dos homens - 72,9 anos e 65,1 anos, respectivamente.

A sobremortalidade masculina nas idades jovens e adultas, principalmente na faixa de 20 a 29 anos, é um dos fatores principais para o aumento da diferença na esperança de vida por sexo. Isto se deve, principalmente, ao impacto das mortes por causas externas (homicídios, acidentes de trânsito, suicídios, quedas acidentais, afogamentos, etc.). $O$ efeito diferenciado das causas externas por sexo indica que sua retirada acarretaria um aumento de 2,5 anos na esperança de vida masculina e de apenas meio ano na feminina.

O diferencial de mortalidade masculina é uma questão de gênero pouco enfatizada pela literatura como tal. Não se trata de subestimar os demais diferenciais por gênero, mas sim de destacar este fato na perspectiva de gênero, e não apenas como 
uma curiosidade dos estudos de mortalidade. Várias questões socioeconômicas estariam associadas a este diferencial.

Um ponto importante para estudos futuros refere-se à hipótese de que o diferencial de mortalidade entre os jovens do sexo masculino e feminino afeta o aumento no hiato de gênero, positivo para as mulheres, medido em termos de anos completos de estudo. Soares (2005) apresenta os fundamentos econômicos para a relação entre reduções na mortalidade e ganhos de escolaridade. $\mathrm{O}$ desempenho educacional associa-se a ganhos de esperança de vida, entre outros, porque um aumento exógeno na esperança de vida permite um maior período de tempo para as pessoas auferirem o retorno de seu investimento, afetando, portanto, sua estratégia de investimento em escolaridade.

Outro ponto importante, associado ao diferencial de mortalidade por sexo e políticas públicas, refere-se ao complexo debate sobre o limite de idade para obtenção de aposentadoria, que é menor para as mulheres, enquanto sua esperança de vida é maior. O tema é controverso, uma vez que a concepção do que venha ser a contribuição das mulheres fora da esfera de trabalho, principalmente no âmbito doméstico, pode justificar tal limite. Uma discussão ponderada sobre esta questão deve considerar os aspectos securitários e os de política social. Para os primeiros, inclusive no caso de benefícios previdenciários privados, este diferencial por sexo deve ser levado em conta seriamente no desenho do equilíbrio atuarial. Este é um tema que certamente entrará na pauta futura.

Uma nova dimensão que vem sendo incorporada ao estudo sobre a esperança de vida é a análise acerca da incapacidade. $\mathrm{O}$ aumento da esperança de vida faz com que uma porcentagem maior de pessoas viva parte de sua vida em estado de incapacidade física ou mental. Interessa saber quantos anos de vida ativa, quer dizer, sem incapacidade, uma pessoa terá. Os dados do Censo Demográfico de 2000 apresentam medidas limitadas de capacidade - por exemplo, a incapacidade de enxergar, ouvir e se locomover (caminhar e subir escadas), além das deficiências permanentes (física e mental). A esperança de vida de 68,6 anos do brasileiro corresponde a 54 anos de vida ativa (78,7\%). A esperança de vida ativa dos homens é de 52,1 anos, equivalendo a $80,4 \%$ de sua esperança de vida, enquanto as mulheres apresentam uma esperança de vida ativa de 55,9 anos, ou seja, $77 \%$ de sua esperança de vida (Baptista, 2003).

A pesquisa Saúde, Bem-Estar e Envelhecimento na América Latina e no Caribe (Sabe), coordenada pela Organização Pan-Americana de Saúde (Opas) e aplicada em um conjunto de grandes cidades da América Latina e do Caribe, inclui um levantamento de dados sobre o município de São Paulo, em 1999.

Baptista (2003) calculou uma tábua de vida ativa para os idosos daquela cidade e percebeu que as mulheres que chegam aos 60 anos de idade esperam viver mais 21,8 anos, dos quais 12,7 anos serão vividos com algum tipo de incapacidade $(58,2 \%)$ e 9,1 anos em estado de plena capacidade. Dos anos vividos em incapacidade pelas mulheres, 5,3 anos serão de incapacidade moderada e 7,4 anos em estados severos de incapacidade. Já os homens que chegam aos 60 anos de idade possuem uma esperança de vida de 17,2 anos, menor do que a das mulheres, mas vivem 9,5 anos sem qualquer tipo de incapacidade e 7,8 anos com alguma incapacidade $(45,1 \%$ da esperança de vida aos 60 anos). Destes, 4 anos serão passados em estados moderados de incapacidade e 3,8 anos em estados severos de incapacidade.

Aos 85 anos de idade, $88,7 \%$ e $77,6 \%$ do tempo de vida restante para mulheres e homens, respectivamente, serão vividos na presença de incapacidade. As mulheres não só passam uma maior proporção de seu tempo de vida em estado de incapacidade, comparativamente aos homens, mas também apresentam maior proporção de tempo de vida vivido estando no estado de incapacidade severa $-50 \%$ superior ao dos homens (Baptista, 2003).

A temática da incapacidade soma-se a vários pontos relacionados à questão do 
envelhecimento, área totalmente interdisciplinar e que tem a demografia como um de seus pilares. Será cada vez maior a interface entre a demografia, a economia do seguro, a economia da saúde e a área da saúde. Vários temas são emergentes a partir desta ênfase no envelhecimento: os arranjos familiares para o cuidado do idoso; a organização do cuidado médico; os limites da sobrevivência e da longevidade; os marcadores biológicos na pesquisa social; a epidemiologia do envelhecimento; o desenvolvimento da gerontologia; etc.

\section{Migração $^{3}$}

A questão da migração internacional é bastante complexa, englobando uma série de dimensões extremamente relevantes. Esta questão envolve fator regional internacional, regulação governamental, emigração, imigração e sistema de informações. ${ }^{4}$

Em que pese a importância histórica dos fluxos imigratórios para o Brasil, a presente análise estará voltada para a questão da emigração de brasileiros para o exterior e seus desdobramentos, inclusive a possibilidade de retorno. Esta ênfase decorre não só de sua importância nos últimos 30 anos do século $X X$, mas também por suas implicações econômicas correntes - por exemplo, por causa das remessas financeiras do exterior para o Brasil e por possíveis implicações futuras, num cenário em que pode ocorrer relativa perda de quadros qualificados de jovens brasileiros nas próximas décadas (brain drain).

A estimativa dos fluxos migratórios para e do Brasil é muito complexa devido a limitações de dados. Carvalho (1996) estimou o fluxo migratório líquido das pessoas com mais de dez anos de idade, mostrando que este era negativo - em torno de 1,8 milhão - nos anos 80 . Infelizmente, o autor afirma que problemas de cobertura entre os censos demográficos de 1991 e 2000 impedem uma estimativa acurada mais recente deste fluxo migratório líquido (Carvalho, 2004). Azevedo (2004) utiliza dados dos consulados brasileiros no exterior para sugerir que o número de brasileiros vivendo no exterior teria passado de 1,5 milhão, em 1997, para cerca de 2 milhões, em 2002. A Tabela 1 foi gerada no âmbito da CNPD, para fins informativos em seminários internacionais. Com todos os problemas de qualidade dos dados, que podem levar a uma subnumeração dos brasileiros vivendo no exterior, os mesmos mostram maior prevalência de brasileiros residindo nos Estados Unidos, no Paraguai e no Japão. Os emigrantes para a Europa ainda não são tão significativos, embora haja informações de que o fluxo dirigidos para Portugal, Espanha e Inglaterra tem aumentado muito.

As limitações destes dados não invalidam a conclusão de que a emigração de brasileiros para o exterior está se tornando um fenômeno cada vez mais importante, ainda que numericamente limitado no que se refere ao peso proporcional na população brasileira total. A discussão acerca dos números de brasileiros no exterior e do saldo migratório líquido é importante e deve ser perseguida.

$O$ tema das remessas financeiras dos brasileiros residentes no exterior é emergente, atraindo interesses do sistema financeiro internacional. $\mathrm{Na}$ ocasião do Encontro de Governadores do BID (Banco Inter-Americano de Desenvolvimento), ocorrido em Okinawa, Japão, em 2005, o presidente do BID, Enrique Iglésias, afirmou que o tema das remessas decorrentes dos fluxos migratórios internacionais era a "Bela Adormecida" do mercado financeiro internacional. Um estudo do BID, realizado pela empresa de pesquisa Bendixen \& Associates, estima que os brasileiros residentes no Brasil recebem, anualmente, cerca de 5,4 bilhões de dólares em remessas de brasileiros residentes no

\footnotetext{
${ }^{3}$ A migração interna possui sua importância própria, mas conforma mais ao debate sobre a distribuição espacial da população brasileira, que, por estratégia deste trabalho, será um tema omitido da análise.

${ }^{4}$ O livro da Comissão Nacional de População e Desenvolvimento (CNPD), denominado Migrações internacionais - contribuições para políticas, de agosto de 2001, demonstra toda esta complexidade.
} 
TABELA 1

Brasileiros emigrantes, segundo local de residência atual

Postos Consulares - 2001

\begin{tabular}{|c|c|c|}
\hline Local de residencia atual & Emigrantes & $\%$ \\
\hline Nova York & 300.040 & 15,89 \\
\hline Miami & 200.005 & 10,59 \\
\hline Boston & 150.005 & 7,95 \\
\hline Washington & 48.001 & 2,54 \\
\hline Houston & 40.140 & 2,13 \\
\hline Los Angeles & 33.007 & 1,75 \\
\hline São Francisco & 15.003 & 0,79 \\
\hline Chicago & 13.002 & 0,69 \\
\hline Estados Unidos & 799.203 & 42,33 \\
\hline Ciudad del Este & 280.059 & 14,83 \\
\hline Assunção & 107.040 & 5,67 \\
\hline Salto del Guaira & 55.005 & 2,91 \\
\hline Paraguai & 442.104 & 23,41 \\
\hline Nagoya & 135.079 & 7,16 \\
\hline Tóquio & 89.891 & 4,76 \\
\hline Japão & 224.970 & 11,92 \\
\hline Zurique & 25.880 & 1,37 \\
\hline Frankfurt & 23.201 & 1,23 \\
\hline Munique & 21.695 & 1,15 \\
\hline Berlim & 15.507 & 0,82 \\
\hline Alemanha & 86.283 & 4,57 \\
\hline Lisboa & 36.070 & 1,91 \\
\hline Porto & 15.520 & 0,82 \\
\hline Portugal & 51.590 & 2,73 \\
\hline Milão & 20.062 & 1,06 \\
\hline Roma & 17.059 & 0,9 \\
\hline Itália & 37.121 & 1,96 \\
\hline Argentina & 35.051 & 1,86 \\
\hline Outros & 211.573 & 11,21 \\
\hline Total & 188.895 & 100,00 \\
\hline
\end{tabular}

Fonte: Ministério das Relações Exteriores, 2002.

exterior. O destinatário recebe cerca de dez remessas por ano, com um valor médio de 428 dólares. Cerca de metade das remessas é originária dos EUA, enquanto o conjunto dos países europeus e o Japão são os dois outros grupos mais importantes. Os brasileiros residentes no Japão (dekaseguis) não só enviam remessas financeiras, mas também retornam com uma substancial poupança para investimento no Brasil, conforme indica a literatura. Martes (2005) estima, a partir de uma amostra de 235 entrevistados, uma média de 6.535 dólares enviados por entrevistado/ano, com uma periodicidade média de 10,1 remessas por ano e um valor médio de 646,10 dólares por remessa. Os dados do FMI (Fundo Monetário Internacional), apresentados por Lozano-Ascencio (2005), mostram uma relativa flutuação nas remes- sas computadas pelo sistema oficial, entre 1995 e 2003. De qualquer forma, o valor das remessas para o Brasil, em 2003, é de cerca de 2 bilhões de dólares, colocando o país em sexto lugar, na América Latina, no que se refere a esses recebimentos. Tais números são relevantes ao se considerar que as remessas variaram entre $3 \%$ e $6 \%$ da pauta de exportações brasileiras e, principalmente, levando-se em conta a pequena proporção da população brasileira que reside no exterior.

A temática das remessas e a análise de seus efeitos para as comunidades locais - por exemplo, a cidade de Governador Valadares-, além das suas implicações macroeconômicas, devem continuar sendo agenda importante de pesquisa. Igualmente relevante é a mensuração destas remessas, distinguindo-se o montante que vem 
registrado oficialmente daquele que entra no país informalmente. O papel das redes migratórias no envio das remessas deve ser estudado, assim como o de agentes informais e/ou institucionalizados, que organizam o fluxo de migração não documentada e, possivelmente, ganham também com as remessas. Outro tópico que merece ser mais estudado é a migração de retorno internacional e a subseqüente inserção do retornado na comunidade e no mercado de trabalho, seja como assalariado, seja nas atividades de negócio, como empreendedor.

Em termos de agenda futura, um tema de potencial relevância é o papel da emigração na inserção do jovem brasileiro na economia global, nos próximos vinte anos.

Historicamente, desde os anos 80, o fenômeno da emigração está presente na realidade brasileira. Alguém poderia especular que, se não houve fugas de cérebros (brain drain) significativas nas duas décadas passadas, um período de estagnação econômica, então não pareceria razoável desenhar um quadro sombrio para o futuro. Este ponto pode ser questionado em dois aspectos. Em primeiro lugar, cada vez mais os jovens de classe média contam com alguma experiência internacional, via intercâmbio ou turismo, uma vez que a barreira da língua é cada vez menor. Em segundo lugar, a demanda por mão-de-obra nos países europeus deve aumentar substancialmente nas próximas décadas, como resultado da fecundidade abaixo do nível de reposição e do envelhecimento populacional. O recurso aos imigrantes africanos fica, lamentavelmente, atenuado com a crescente barreira de discriminação racial e religiosa, além dos problemas de contingente populacional que o continente enfrentará, num futuro próximo, devido à mortalidade por Aids.

Neste contexto, do ponto de vista dos países europeus, o perfil do imigrante latinoamericano é bastante atrativo. Se isto for verdadeiro, então a possibilidade de se perder um segmento dos jovens qualificados brasileiros (ensino médio ou mais) para o mercado de trabalho internacional é algo bastante concreto, o que coloca o brain drain na pauta de estudos futuros.

\section{A dinâmica demográfica e a estrutura etária}

O crescimento da população e as mudanças em sua estrutura etária são primordialmente afetados pelas tendências da fecundidade e da mortalidade e, em alguma medida, pelo saldo migratório internacional. A queda na mortalidade e os ganhos de esperança de vida pouco afetam a estrutura etária, num país que apresenta altas taxas de crescimento populacional. Sendo assim, durante um longo período, os ganhos de esperança de vida aumentaram a longevidade das gerações de nascimento, mas não envelheceram a população brasileira. Por outro lado, a queda na taxa de fecundidade total afeta bruscamente a estrutura etária da população, levando a uma redução na proporção de dependentes (crianças de 0 a 14 anos) e a um crescente envelhecimento da população (idosos de 60 anos e mais).

Um ponto importante para a relação entre estrutura etária e projeção populacional, a ser discutido a seguir, refere-se ao fato de que os ganhos futuros de esperança de vida ainda terão impacto relativamente pequeno sobre a estrutura etária populacional. Por outro lado, o impacto da fecundidade futura tenderá a ser mais diluído, dada a baixa fecundidade já alcançada. Dessa forma, grande parte da mudança na estrutura etária futura será afetada pela inércia populacional, que possui grande componente alicerçado na fecundidade passada.

\section{A projeção populacional do IBGE e a estrutura etária}

O documento base deste item é uma revisão da projeção populacional do IBGE até 2050, divulgada por meio eletrônico no site do IBGE, em outubro de 2004. Não se pretende discutir a metodologia de projeção do IBGE, nem mesmo sua precisão. O objetivo é tomar uma fonte oficial para discutir a tendência futura da estrutura etária. De qualquer forma, alguns alertas sobre os pressupostos desta projeção devem ser emitidos.

A projeção toma por base a população enumerada no Censo Demográfico 
de 1980 , assumindo que a cobertura do Censo Demográfico de 2000 é a ideal. O documento argumenta que a base em 1980 permite uma projeção ligeiramente superior à população do censo de 1991 e à contagem de 1996, mas uma projeção bastante mais próxima da população total e por idade do censo de 2000.

Sem entrar em maiores detalhes sobre as estimativas de mortalidade da projeção populacional, cumpre destacar que a tábua de mortalidade utilizada para 2000 pressupõe uma esperança de vida ao nascer de 70,4 anos para ambos os sexos, um pouco acima dos 68,6 anos apresentados pela estimativa PNUD/Cedeplar mostrada anteriormente. De qualquer forma, diferenças na esperança de vida e na tábua de mortalidade devem afetar a estrutura etária da população projetada em menor proporção do que diferenças nas projeções da taxa de fecundidade total.

Uma questão cada vez mais importante nos próximos anos será a confiabilidade nas estimativas de mortalidade, principalmente no que tange às estimativas de mortalidade adulta. Mais importante do que o papel destas estimativas nas projeções populacionais é o seu papel nos cálculos atuariais dos fundos de pensão e dos seguros, tanto para o setor público quanto o privado. Fontes de dados e metodologias alternativas devem ser cada vez mais incentivadas.

A projeção da taxa de fecundidade total é bastante conservadora, quando se tem conta que a estimativa da mesma em 2000 era de 2,4 filhos por mulher, com base no censo demográfico, sendo que esta taxa chega a 2,1 filhos por mulher (nível de reposição) na PNAD de 2003. A projeção de fecundidade utilizada pelo IBGE assume que o nível de reposição só será alcançado entre 2015 e 2020. A reflexão acerca da fecundidade futura, realizada anteriormente, mostra claramente que a fecundidade bem abaixo do nível de reposição não está fora de questão. Uma estimativa mais alta da fecundidade tem implicações tanto na estrutura etária quanto no tamanho da população total no século XXI. A despeito das questões anteriormente mencionadas, conclama-se a necessidade do desenho de projeções com cenários alternativos para o comportamento da taxa de fecundidade total, entre 2005 e 2030, mas opta-se por utilizar estas projeções oficiais disponíveis apenas para realçar as tendências básicas de mudanças na estrutura etária.

Um outro pressuposto delicado na referida revisão de projeção é o de população fechada. O saldo migratório líquido negativo, indicado pela literatura específica, dificilmente cairia a zero nos anos 90 . O pressuposto de um saldo migratório nulo ou de uma população fechada pode se justificar na argumentação de ajustes da projeção ad hoc para a estrutura etária entre os períodos censitários, mas provavelmente reflete problemas na qualidade das estimativas de mortalidade adulta (eventualmente subestimadas). $O$ ajuste, sem o devido realismo dos componentes, pode gerar conseqüências nas estimativas da população total futura.

O Gráfico 1 mostra a descrição clássica da razão de dependência total (jovens mais idosos), jovens (0-14/15-64) e idosos (65 e mais/15-64) entre 1980 e 2050. A razão de dependência de jovens refere-se, mais apropriadamente, à participação do segmento infantil na população ativa, que declina durante quase todo o período descrito, mas com maior queda precisamente nos anos 90 . O crescimento mais acentuado da razão de dependência dos idosos se dará a partir de 2010. A razão de dependência total apresenta maior queda entre 1980 e 2000 e menor declínio até 2025, ponto a partir do qual esta razão começa a aumentar, como resultado do peso da razão de dependência dos idosos. Esta descrição clássica da projeção da razão de dependência já foi por demais descrita pela literatura que trata das implicações da dinâmica demográfica sobre a estrutura etária. Um refinamento da participação de segmentos da população em idade ativa sobre a população total pode ser esclarecedor.

A Tabela 2 mostra o aumento da participação da PIA sobre a população total, entre 1980 e 2025. O crescimento é substancial entre 1980 e 2000 , sendo bem menor até 2025. O chamado segmento 
GRÁFICO 1

Projeção da razão de dependência

Brasil - 1980-2050

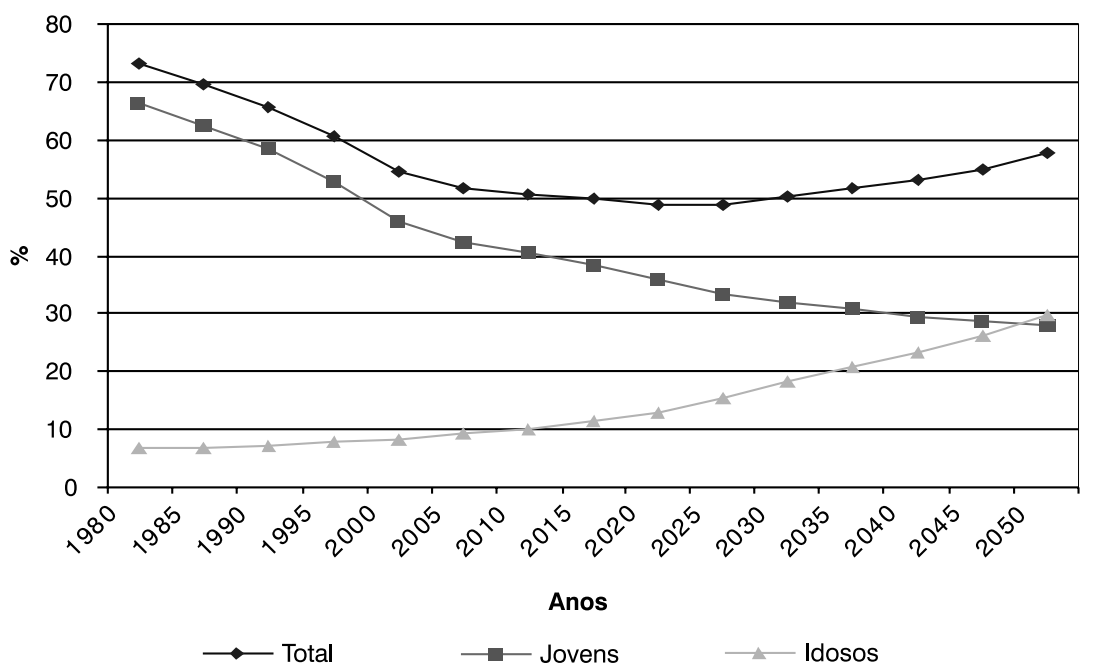

Fonte: Oliveira, Albuquerque e Lins (outubro de 2004); IBGE. Projeção da População do Brasil por Sexo e Idade para o Período 1980-2050 - Revisão 2004.

TABELA 2

Projeção da participação da PIA na população total, por faixa etária

Brasil-1980-2050

\begin{tabular}{ccccc}
\hline Anos & $\mathbf{1 5 - 2 4}$ anos & $\mathbf{2 5 - 4 4}$ anos & $\mathbf{4 5 - 6 4}$ anos & $\mathbf{1 5 - 6 4}$ anos \\
\hline 1980 & 21,11 & 24,57 & 12,07 & 57,75 \\
1985 & 20,73 & 25,80 & 12,49 & 59,02 \\
1990 & 19,53 & 27,89 & 12,89 & 60,31 \\
1995 & 19,20 & 29,47 & 13,61 & 62,29 \\
2000 & 19,74 & 30,14 & 14,90 & 64,78 \\
2005 & 19,08 & 30,40 & 16,50 & 65,97 \\
2010 & 17,09 & 30,70 & 18,57 & 66,36 \\
2015 & 15,94 & 30,58 & 20,24 & 66,76 \\
2020 & 15,82 & 29,99 & 21,40 & 67,21 \\
2025 & 15,63 & 29,18 & 22,41 & 67,23 \\
2030 & 14,92 & 28,17 & 23,51 & 66,60 \\
2035 & 14,04 & 27,66 & 24,22 & 65,91 \\
2040 & 13,43 & 27,48 & 24,47 & 65,38 \\
2045 & 13,03 & 27,05 & 24,52 & 64,60 \\
2050 & 12,62 & 26,34 & 24,39 & 63,34 \\
\hline
\end{tabular}

Fonte: Oliveira, Albuquerque e Lins (outubro de 2004); IBGE. Projeção da População do Brasil por Sexo e Idade para o Período 1980-2050 - Revisão 2004.

jovem da PIA, definido pela população de 15 a 24 anos, apresenta ligeiro declínio da participação na população total entre 1980 e 2000, diminuindo mais intensamente até 2015 e de forma mais leve até 2050. O segmento adulto da PIA, que compreende o grupo etário de 25 a 44 anos, é composto pelas pessoas que auferem os ganhos de experiência nos seus rendimentos, além de passarem pela fase do ciclo de vida associada à constituição da família e criação dos filhos. Este segmento cresce entre 1980 e 2000, aumentando ligeiramente sua participação na população total até 2010 e declinando um pouco a partir deste período. $\mathrm{O}$ segmento que mais cresce entre $2000 \mathrm{e}$ 
2020 é o da PIA madura, compreendendo aqueles com 45 a 64 anos de idade. Em termos gerais, esta PIA madura já apresenta decréscimo de rendimento médio, se comparada ao grupo etário anterior. $\mathrm{O}$ pico da curva de rendimento por idade tende a ser atingido entre os 40 e 50 anos de idade. Há, hoje, um amplo debate sobre o potencial de produtividade da PIA madura no mundo desenvolvido de baixa fecundidade e envelhecimento populacional, tema cada vez mais relevante para o país. O decréscimo da participação da PIA jovem e o crescimento da participação da PIA madura são os fatos novos ditados pela dinâmica demográfica na primeira metade do século XXI, com uma relativa constância (sanduíche) do segmento da PIA adulta.

Um outro ponto relacionado com a estrutura etária refere-se à dinâmica da razão de sexos nos segmentos etários relevantes para o mercado de casamento, que tem o número de homens de 20 a 29 anos de idade no numerador e o de mulheres de 15 a 24 anos no denominador. Esta razão apresenta uma defasagem de cinco anos entre o intervalo masculino e feminino para indicar a demanda média por casamentos/ uniões, na qual, geralmente, o parceiro do sexo masculino é mais velho. Por causa desta defasagem etária, espera-se que as flutuações demográficas de curto prazo, ditadas pela existência de uma grande coorte de jovens nos anos 90 e de um declínio da mesma nas duas primeiras décadas do século $X X I$, imporão uma flutuação no mercado de casamento. $O$ Gráfico 2 indica que esta razão era próxima a $80 \%$ em 1980 , aumentou para $95 \%$ em 1990, se estabilizou com um ligeiro declínio entre 1990 e 2000 , voltando a subir para $96 \%$ em 2005 e para $105 \%$ em 2010. Haverá um ligeiro decréscimo entre 2010 e 2020, mas a razão de sexo voltará a subir acima de $100 \%$ entre 2030 e 2050 . Este maior aquecimento no mercado de casamento não corresponde ao padrão histórico brasileiro, com razão de sexos para casamento abaixo de $100 \%$. A experiência do qüinqüênio 2005-2010 deve ser observada com atenção, pois mostra um grande aquecimento neste mercado.

GRÁFICO 2

Projeção da razão sexo, por faixa etária Brasil-1980-2050

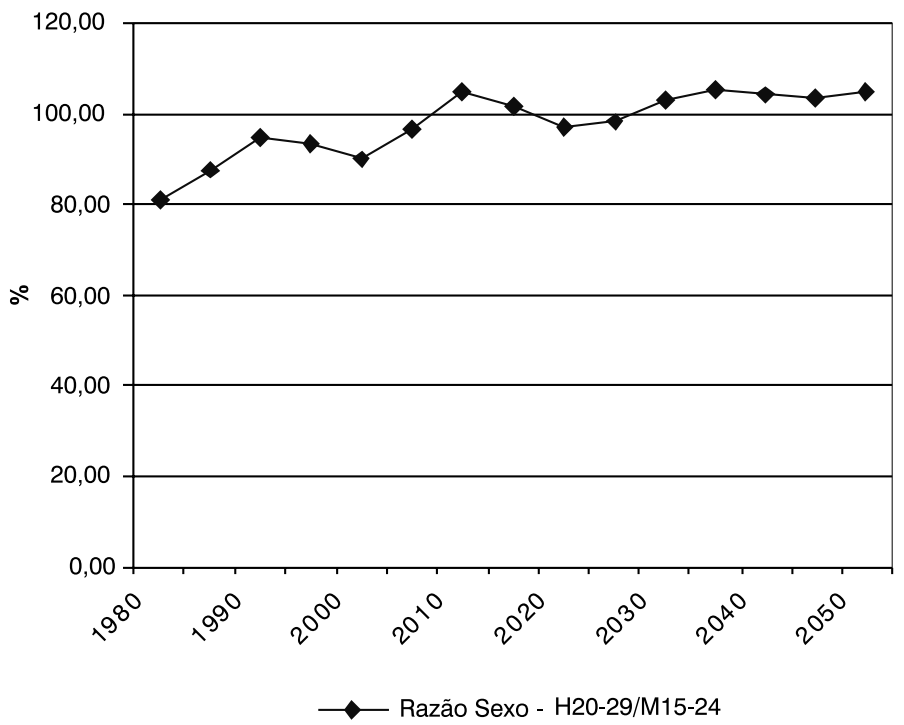

Fonte: Oliveira, Albuquerque e Lins (outubro de 2004); IBGE. Projeção da População do Brasil por Sexo e Idade para o Período 1980-2050 - Revisão 2004. 
Um tópico bastante importante para investigação será relacionar este aquecimento no mercado de casamento com a idade mediana de formação da união, a qual tem se mantido praticamente constante ao longo das gerações de mulheres brasileiras - em torno de 21 anos. Estudo feito para Belo Horizonte, comparando duas coortes de mulheres - 20 a 29 anos e 50 a 59 anos -, sugere que não há diferenças na idade por ocasião da primeira união das mulheres das duas gerações. Ao longo dos 20 a 30 anos que separam estas coortes, a idade mediana na primeira união, naquela capital, permaneceu em torno de 23 anos (Simão et al., no prelo).

O debate sobre a eventual operação de um efeito tempo positivo na fecundidade brasileira, causando queda ainda maior abaixo do nível de reposição, trata da possibilidade de emergência do chamado padrão europeu, marcado pelo aumento da idade de casamento ou de primeira união, além do adiamento do nascimento do primeiro filho. Se a razão de sexo aquecer o mercado de casamento nos próximos anos, então as chances de a idade na primeira união aumentar são reduzidas. É possível que até mulheres com mais de 30 anos de idade, ainda solteiras, sejam atraídas para o mercado de casamento com homens mais jovens, em decorrência do "marriage squeeze" ${ }^{5}$ previsto pela razão de sexo.

Uma possibilidade de se observar a operação do efeito tempo decorreria da eventualidade de um adiamento do nascimento do primeiro filho, mesmo que dentro de uma união já formada. Esta possibilidade não é plausível até o presente, uma vez que a concentração da fecundidade se dá nas idades mais jovens, entre 15 e 24 anos, precedida ou não pela primeira união.

Um tema da maior relevância para o futuro imediato será cotejar a relação entre a tendência de adiamento do casamento e do primeiro filho, como decorrência do prolongamento do período devotado à freqüência escolar, visando o aumento da escolaridade, e a tendência de casamento imediato, como resultado do aquecimento no mercado de casamentos.

\section{Implicações da dinâmica demográfica no nível macro}

Nesta segunda parte, faz-se a ligação entre a dinâmica demográfica recente e suas perspectivas, neste início de século, com três conjuntos de questões: a demografia dos efeitos de composição; o dividendo demográfico; e as transferências intergeracionais.

\section{A demografia dos efeitos de composição}

Os efeitos de composição podem ser afetados pela dinâmica demográfica, com implicações claras para as políticas públicas. Os níveis de fecundidade discutidos anteriormente mostram altos diferenciais por escolaridade materna e renda per capita domiciliar. Não há dúvidas de que a alta fecundidade observada nas famílias com mães menos escolarizadas e com renda per capita domiciliar baixa afeta o bem-estar destas famílias. Não há nada de "neomalthusiano" nesta constatação. Existe, simplesmente, a diluição dos parcos recursos disponíveis para estas famílias numerosas.

Se, por um lado, o declínio generalizado da fecundidade no Brasil, apresentado anteriormente, implica um maior grau de flexibilidade das famílias para se adaptarem às pressões de recursos, por outro, o diferencial de fecundidade observado indica segmentos de famílias menos dotadas (em educação e/ou renda), provavelmente enfrentando dificuldades de ajustes às pressões por recursos. É possível imaginar uma crescente participação relativa dos nascimentos de filhos de mães menos escolarizadas e de famílias mais pobres no total de nascimentos. Isto significa que as coortes de nascimento, ao serem observadas num futuro de 15 a 20 anos, poderiam apresentar maior participação de jovens oriundos de famílias menos dotadas em

\footnotetext{
${ }^{5}$ Termo geralmente utilizado para definir uma escassez relativa de mulheres no mercado de casamento.
} 
escolaridade e renda domiciliar per capita. Se isto ocorresse, teríamos, claramente, um problema social marcado pelo aumento da carência de background das coortes futuras brasileiras. Este tipo de cenário demandaria políticas sociais ativas para compensar a deficiência de background familiar.

Há um problema de raciocínio na extrapolação acima. $\mathrm{O}$ diferencial de taxas de fecundidade por atributos de escolaridade materna e renda domiciliar per capita seria determinante da composição social de uma coorte no período futuro, mas isto só ocorreria se a composição das mães por escolaridade e renda ficasse inalterada.

Uma análise da coorte de 0 a 4 anos em diferentes períodos (captada por pesquisa domiciliar) refletirá, grosso modo, os nascimentos no período de análise. $A$ composição social desta coorte de 0 a 4 anos, nos vários períodos, representa a interação entre o diferencial de fecundidade por atributos e o número de mães por escolaridade ou renda familiar per capita. Além disso, na ausência de mobilidade, essa coorte representará a composição de jovens de 15 a 19 anos de idade, 15 anos mais tarde. Em outras palavras, a análise das crianças de 0 a 4 anos por background familiar simula a população de jovens de 15 a 19 anos, 15 anos depois, controlada pelo background familiar quando no momento do nascimento, o qual, por suposição, permanece constante.
Os dados do Gráfico 3 indicam que a persistência do diferencial de fecundidade por escolaridade materna, discutida anteriormente, não causou concentração de nascimentos originados por mães de baixa escolaridade, pois houve um efeito de composição compensador. A porcentagem de crianças de 0 a 4 anos de idade, geradas por mães que tinham de 0 a 3 anos de estudo completos, representava cerca de $48 \%$ do total de nascimentos em 1983. Em 2003, após uma queda monotônica, a participação chega a cerca de $21 \%$.

Os dados do Gráfico 4 confirmam que este resultado decorre de um efeito de composição, marcado tanto pelo notável declínio no número de mães com baixa escolaridade ( 0 a 3 anos de estudo) quanto pelo aumento no número de mães com mais alta escolaridade (9 anos ou mais de estudo). Este resultado sugere que a dinâmica demográfica recente favorecerá a melhoria no desempenho escolar dos jovens de 15 a 19 anos, no futuro. Enquanto $47,9 \%$ das crianças de 0 a 4 anos, em 1983, eram filhos de mães com baixa escolaridade, representando as condições dos jovens de 15 a 19 anos em 1998, esta porcentagem passa para $34,3 \%$ dos jovens de 15 a 19 anos, em 2008, e para $21 \%$ em 2018. Aceitando-se a proposição de que filhos de mãe com escolaridade mais alta têm um melhor desempenho escolar, estes dados mostram que, do ponto de vista do

Distribuição das crianças de 0 a 4 anos, segundo anos de estudo da mãe Brasil-1983-2003

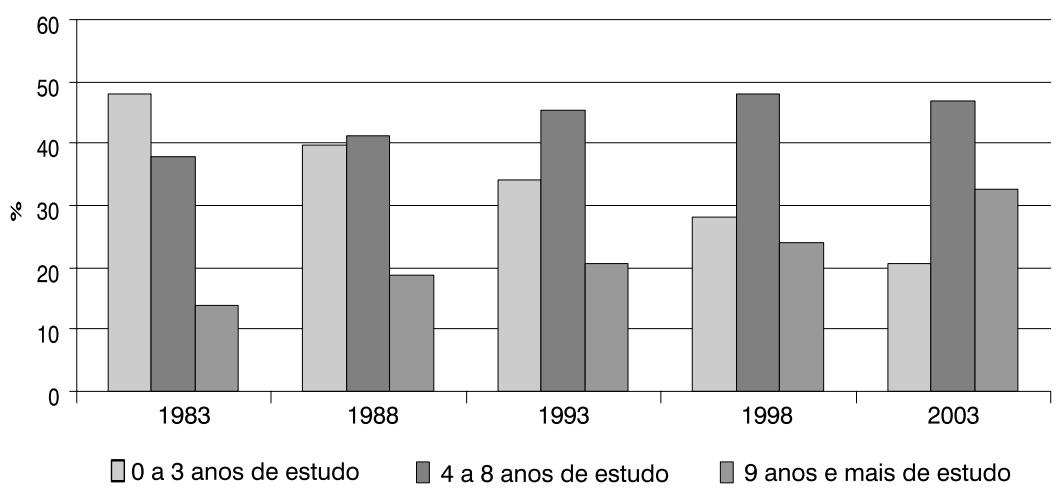

Fonte: IBGE. Pesquisa Nacional por Amostra de Domicílios - PNAD (tabulação do autor a partir dos microdados). 
desempenho educacional dos jovens nos níveis educacionais mais elevados (ensino médio e superior), as condições demográficas futuras favorecem a política educacional. Sendo assim, uma política governamental de transferências de recursos, voltada para os objetivos de desempenho educacional dos jovens, deveria ser focalizada naquele segmento de filhos de mães com baixa escolaridade. Um exemplo de política nesta área seria a provisão de ensino em tempo integral para os filhos de mães com baixa escolaridade.

Os dados do Gráfico 5 mostram que a distribuição das crianças de 0 a 4 anos, por renda familiar per capita, se alterou entre 1983 e 2003. Tais mudanças, no entanto, não foram de uma forma tão radical quanto as observadas nas características educacionais das mães. Houve um declínio no porcentual de filhos nas famílias com renda per capita de até $1 / 4$ de salário mínimo, que foi compensado pelo aumento no número de filhos em famílias com esse rendimento entre $1 / 2$ e 1 salário mínimo, mais do que proporcionalmente ao aumento nos demais estratos de renda familiar per capita, superiores a um salário mínimo.

$O$ contraste do dinamismo entre o crescimento da porcentagem de jovens

GRÁFICO 4

Distribuição das mães de filhos de 0 a 4 anos, segundo anos de estudo Brasil-1983-2003

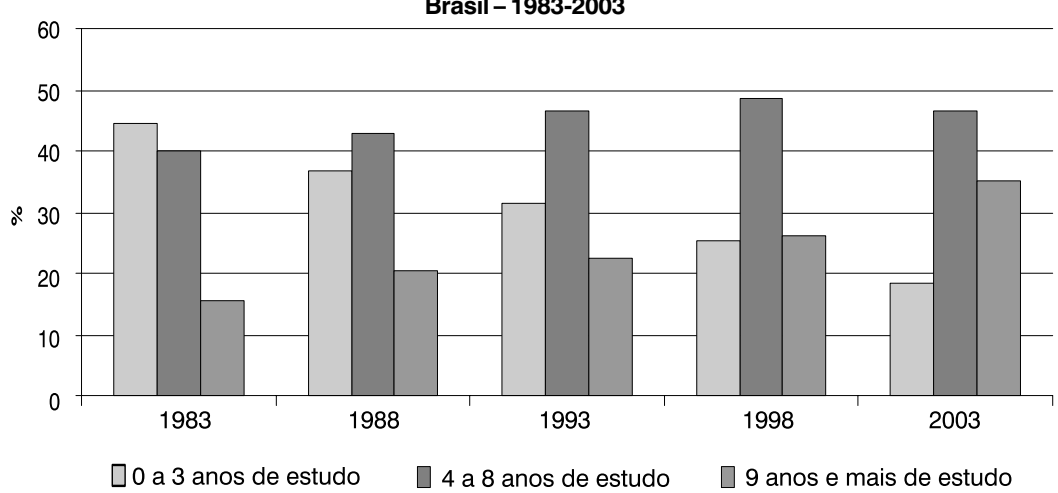

Fonte: IBGE. Pesquisa Nacional por Amostra de Domicílios - PNAD (tabulação do autor a partir dos microdados).

GRÁFICO 5

Distribuição das crianças de 0 a 4 anos, segundo classes de renda familiar per capita (1) Brasil - 1983-2003

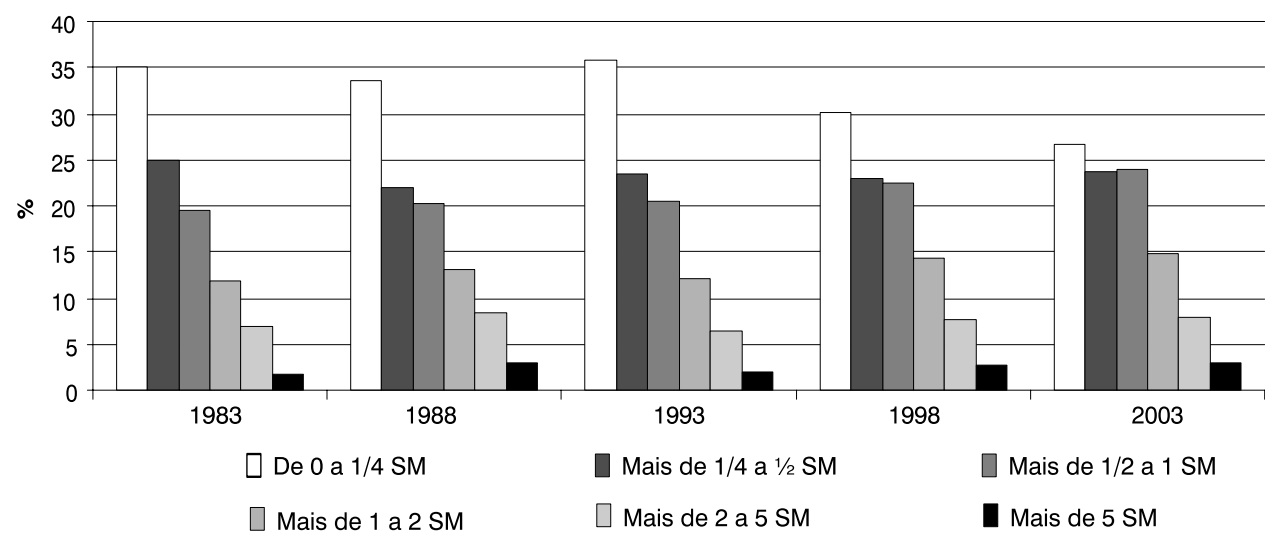

Fonte: IBGE. Pesquisa Nacional por Amostra de Domicílios - PNAD (tabulação do autor a partir dos microdados).

(1) Em salários mínimos. Os rendimentos foram deflacionados para 10 de janeiro de 2003 e classificados segundo o salário mínimo vigente na época $(R \$ 200,00)$. 
nascidos de mães com maior escolaridade e a relativa estabilidade da proporção de filhos nascidos por estratos de renda familiar per capita coloca um claro efeito na estrutura de composição, que pode afetar o planejamento de políticas futuras para os jovens, principalmente no foco de políticas educacionais.

Claramente, as famílias de renda mais baixa possuem restrições de crédito para investir na educação de seus filhos. A melhoria na escolaridade das mães desloca para cima a demanda por educação nestes segmentos, mas a menor mobilidade de renda familiar no tempo mantém as restrições de crédito. As famílias mais pobres possuem restrições de crédito, que levam a um subinvestimento em capital humano.

Vários estudos de nível micro demonstram que a renda familiar per capita é importante determinante da escolaridade média dos filhos. Sendo assim, a mobilidade educacional da mãe e a relativa estagnação da renda familiar per capita confirmam a necessidade de se continuar com políticas de transferência de renda, condicionadas ao desempenho escolar. Programas nos moldes do Bolsa Família, ora em vigor no país, devem ser pensados até mesmo para níveis maiores de escolaridade, como o ensino médio, tendo em vista o impacto negativo das restrições de crédito acima discutidas.

Concluindo, esta análise da demografia dos efeitos de composição resulta em duas proposições de políticas públicas. Em primeiro lugar, há uma carência de políticas públicas focadas nos filhos de mães com baixa escolaridade, cujo segmento representa um quinto dos nascimentos em 2003 e será a população de 15 a 19 anos em 2018. Apenas uma política de transferência de renda, acompanhada pela provisão de atenção integral na escola, permitiria alguma melhoria substancial na escolaridade deste segmento. Em segundo lugar, há aumento na demanda por escolaridade elevada, ditada pelo aumento de filhos nascidos de mães com média e alta escolaridade; uma parcela relevante destas mães é composta por pobres, uma vez que a variação da porcentagem de mães por renda é bem menos clara. Isto significa que o aumento de escolaridade da mãe, acompanhado menos que proporcionalmente pelo aumento de renda per capita domiciliar implica uma potencial restrição de crédito. Apenas políticas que afetem as restrições de crédito das famílias pobres permitirão que esta virtuosidade potencial se materialize em maior escolaridade das gerações futuras do país.

\section{O dividendo demográfico}

O chamado "dividendo demográfico", também denominado de "janela de oportunidades", quando discutido por literatura menos economicista, é um fenômeno benéfico para a sociedade em termos econômi$\cos$, associado às conseqüências diretas do declínio da fecundidade sobre a estrutura etária durante e imediatamente após a transição demográfica. Estas mudanças na estrutura etária, discutidas anteriormente para o caso brasileiro, trazem conseqüências sobre o crescimento econômico e a estrutura de gastos públicos.

Várias vertentes fazem uso desta noção de dividendo demográfico, muitas vezes entendida como uma mera "apologia controlista" de cunho "neomalthusiano" para justificar o planejamento familiar "controlista". A vertente "neomalthusiana" vê o dividendo demográfico como uma rationale para que se defenda o controle populacional, implementado por intermédio de uma política dirigida de planejamento familiar, conforme formulado originalmente por Coale e Hoover, para o caso da Índia, e seguido por aplicações mais diretas de modelos de crescimento econômico, como o de Solow. Outras vertentes identificam o "dividendo demográfico", ou "janela de oportunidades", como uma potencialidade lógica, decorrente das conseqüências diretas do declínio da fecundidade sobre a estrutura etária.

Esta potencialidade lógica pode ser aproveitada ou não pelos países durante o período de transição demográfica. O seu aproveitamento dependerá de vários aspectos, tais como as condições econômicas, institucionais de Estado, de operação do setor financeiro e de comportamento da 
família, entre outras. A coleta deste dividendo não é mecanicamente determinada pelas condições demográficas.

Num caso como o brasileiro, cujo declínio da fecundidade no século XX chegou praticamente à beira do nível de reposição, não faz mais sentido discutir o debate sobre o dividendo demográfico como sendo uma rationale para algum tipo de política "controlista”. Não há como pensar planejamento familiar, hoje, em termos de controle do crescimento populacional, uma vez que ele atende a outras demandas na área de saúde reprodutiva, dentro dos preceitos da Conferência de Cairo.

Uma vez desqualificada a discussão sobre o dividendo demográfico como parte da esfera "controlista", o que resta do debate? Resta discutir o dividendo demográfico, tendo em vista o planejamento das políticas de Estado que incorporem o componente populacional, visando o desenvolvimento econômico e social do país. A agenda sobre o dividendo demográfico consiste na identificação de pontos de estrangulamento e oportunidades geradas pela dinâmica presente e futura da estrutura etária, podendo ser analisado na perspectiva macro ou micro. Aqui, apenas os aspectos macro serão considerados.

Um debate macro antigo, associado ao que hoje se denomina dividendo demográfico, mas que tradicionalmente era "neomalthusiano" e, em algum momento, virou "janela de oportunidades", refere-se ao impacto da razão de dependência jovem (ou infantil) sobre o gasto com educação.

Riani (2001) estuda o impacto da razão de dependência sobre a taxa de matrícula, taxa de cobertura, taxa de eficiência e razão professor/aluno, entre outras variáveis dependentes associadas com o gasto público com educação. O tamanho da coorte em idade escolar afeta negativamente indicadores de quantidade e de qualidade (repetência) escolar. Estes resultados confirmam a operação de um certo dividendo demográfico na área de educação. Em sua tese de doutoramento, utilizando modelos hierárquicos, Riani (2005) confirma o papel da razão de dependência macro (no município) sobre o comportamento de quantidade e qualidade do ensino no nível micro ou familiar. É possível concluir que o crescimento espetacular da matrícula e da cobertura escolar, nos anos 90, deve-se, em parte, ao papel do Fundef (Fundo de Desenvolvimento do Ensino Fundamental e de Valorização do Professor) e às prioridades governamentais, mas é inegável a importância da grande queda na razão de dependência para facilitar o estrondoso aumento na cobertura escolar observado no período. Relatórios de projeção conduzidos pelo autor deste trabalho indicam que o crescimento da matrícula escolar, no futuro, decorrerá muito mais do crescimento na taxa de matrículas por série e idade do que do aumento da população em idade escolar. Os grupos etários da população em idade escolar apresentam flutuações positivas e negativas até 2020 , mas, do ponto de vista total, não há pressão de crescimento da população em idade escolar.

Uma identidade básica que define a renda per capita ajuda a explicitar a base da hipótese macroeconômica do dividendo demográfico. A referida identidade é descrita na equação (1) e norteia a literatura sobre crescimento e renda per capita.

$$
\begin{aligned}
& \mathrm{Y} / \mathrm{P}=(\mathrm{Y} / \mathrm{O}) \times(\mathrm{O} / \mathrm{P}) \\
& \text { Definindo-se: } \\
& \mathrm{Y} / \mathrm{P}=\mathrm{y}=\text { renda per capita } \\
& \mathrm{Y}=\text { renda nacional } \\
& \mathrm{P}=\text { população total } \\
& \mathrm{O}=\text { número de ocupados }
\end{aligned}
$$

Definindo-se $\Delta$ como a variação no tempo para todos os parâmetros de (1), temse:

$\Delta y=\Delta y^{0}+\Delta 0-\Delta P$

Definindo-se:

$\Delta \mathrm{y}=$ crescimento da renda per capita

$\Delta \mathrm{y}^{\circ}=$ crescimento da produtividade

$\Delta 0=$ crescimento dos ocupados

$\Delta \mathrm{P}=$ crescimento populacional

A literatura econômica enfatiza o estudo sobre a produtividade econômica, principalmente tendo por base os modelos de crescimento, a maioria dos quais considerava o total de ocupados e a população sem 
distinção, pressuposto que faz sentido no longo prazo, em que a população é estável e, por isto mesmo, apresenta todos os segmentos etários crescendo na mesma proporção. A incorporação da diferença entre o crescimento dos ocupados e o aumento populacional é a preocupação central que trouxe o debate sobre o dividendo demográfico para a discussão econômica.

O crescimento dos ocupados é determinado pela elevação da população em idade ativa e a taxa de ocupação (que é a diferença entre a taxa de participação na $\mathrm{PEA}^{6}$ e a de desemprego). A literatura sobre o dividendo demográfico enfatiza o crescimento da população em idade ativa como principal determinante do aumento dos ocupados. Nesta linha, em termos da equação 2 , controlando-se pelo crescimento da produtividade, objeto central da preocupação dos economistas, e assumido independente da estrutura etária, o dividendo demográfico seria um bônus extra, causado pela diferença entre o crescimento da população em idade ativa (PIA), utilizada como proxy para a expansão dos ocupados, e o crescimento populacional.

A diferença positiva entre o crescimento da PIA e a elevação populacional ocorre precisamente durante o período da transição demográfica, e tende a perder força à medida que a inércia populacional é reduzida e a população se aproxima da estabilidade populacional. O Gráfico 2 mostra que, potencialmente, a fase mais dinâmica do dividendo demográfico no Brasil ocorreu entre 1980 e 2000. Há uma previsão de sua operação até 2025 , mas com um crescimento em ritmos bem menores.

Um primeiro exercício de mensuração do impacto do dividendo demográfico sobre o crescimento da renda per capita brasileira é apresentado a seguir. As estimativas seguem o debate econômico sobre a convergência de renda e as especificações econométricas dos modelos de crescimento da renda, discutidas no livro Population Matters, editado por Birdsall, Kelley e
Sinding (2001). O teste utiliza a renda per capita domiciliar média dos municípios brasileiros, tendo por base os dados do IBGE apresentados no Atlas do Desenvolvimento Humano do Brasil (PNUD), 2003.

A variável dependente:

- $\mathrm{y}_{\mathrm{r}}=$ taxa de crescimento anual da renda per capita entre 1991 e 2000, medida em termos de renda individual coletada nos censos demográficos.

As variáveis independentes são:

- Lny91 = o logaritmo da renda per capita municipal em 1991;

- Educadu = a média de anos de estudo da população adulta no município em 1991;

- Lnpiapop = o logaritmo da razão entre a população em idade ativa e a população total em 1991;

- Difgrpp = a diferença entre o crescimento da PIA e o aumento populacional entre 1991 e 2000.

A elevação da renda per capita, nos anos 90, foi afetada negativamente pelo nível desse rendimento nos municípios, no início da década, um resultado que conforma com a hipótese da convergência da renda. A proporção da população total em idade ativa afeta positivamente e de forma significante o crescimento da renda per capita na década de 90 , conforme previsto pela hipótese do dividendo demográfico (Tabela 3). A causalidade destas estimativas poderia ser questionada, principalmente, devido ao possível viés de simultaneidade da equação. Estimativas utilizando variáveis instrumentais são apresentadas na Tabela 4, confirmando tanto a convergência da renda per capita municipal quanto o efeito positivo do dividendo demográfico.

O Gráfico 6 indica a importância da convergência da renda municipal no modelo do crescimento da renda per capita municipal. Já o Gráfico 7 confirma a força do dividendo demográfico no crescimento da renda per capita municipal. O impacto da variável Lnpiapop é positivo e substancial -

${ }^{6}$ PEA significa população economicamente ativa. 
TABELA 3

Determinantes do crescimento da renda per capita

\begin{tabular}{l|rc|c}
\hline Variável Dependente: Ygr & \multicolumn{3}{|c}{} \\
\hline Varáveis Independentes & Coeficiente & P>t & Número de Observações 5507 \\
InY91 & $-0,057992$ & 0,000 & $\mathrm{~F}(4,5502)=751,08$ \\
Educadu & 0,0121332 & 0,000 & $\mathrm{R} 2=0,4429$ \\
Inpiapop & 0,2398017 & 0,000 & \\
difgrpp & 1,386553 & 0,000 & \\
constante & 0,3917059 & 0,000 & \\
\hline
\end{tabular}

Fonte: Atlas do Desenvolvimento Humano no Brasil, PNUD, Ipea, Fundação João Pinheiro, 2003. Estimativas do autor usando o pacote estatítico stata.

TABELA4

Modelo Tabela 3 com variáveis instrumentais

Estimativa por dois estágios mínimos quadrados

\begin{tabular}{|c|c|c|c|}
\hline Variável Dependente: Ygr & & & \\
\hline Varáveis Independentes & Coeficiente & $P>t$ & \\
\hline $\ln Y 91$ & $-0,0857083$ & 0,003 & Número de Observações 5507 \\
\hline Educadu & 0,0082641 & 0,338 & $F(4,5502)=751,08$ \\
\hline Inpiapop & 0,6595232 & 0,018 & $\mathrm{R} 2=0,4429$ \\
\hline difgrpp & 7,401432 & 0,075 & \\
\hline constante & 0,7159253 & 0,002 & \\
\hline
\end{tabular}

Fonte: Atlas do Desenvolvimento Humano no Brasil, PNUD, IPEA, Fundação João Pinheiro, 2003.

Estimativas do autor usando o pacote estatítico stata.

Variáveis Instrumentadas: Iny91, Inpiapop, difgrpp

Variáveis Instrumentais: educadu, pop70, pgr7080, pgr8091, exp-vida70, exp-vida80, y70, y80, analf.70, analf80.

GRÁFICO 6

Taxas de crescimento da renda per capita municipal

Brasil-1991-2000

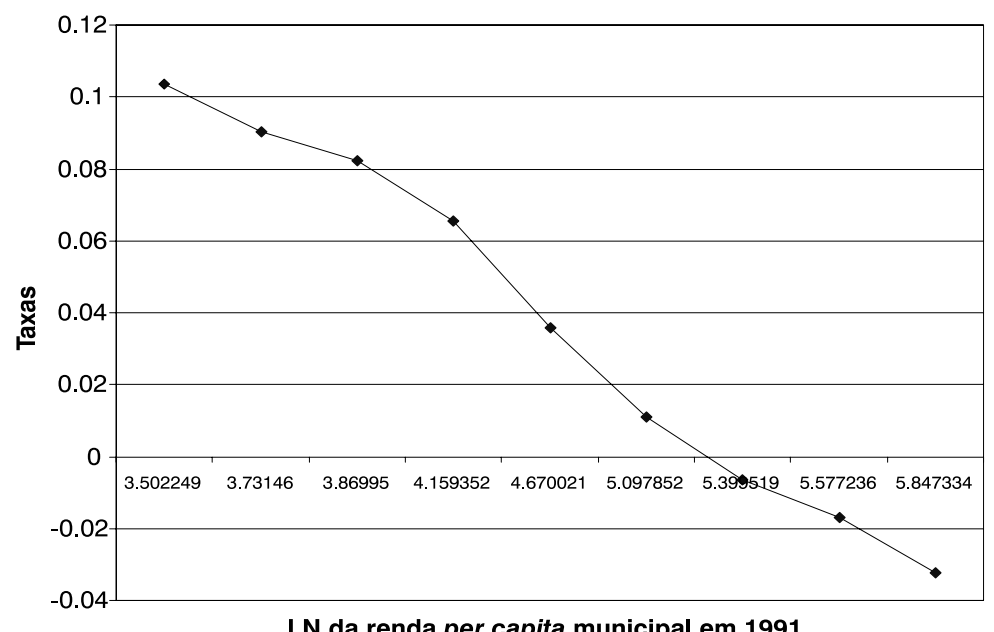

LN da renda per capita municipal em 1991

Fonte: Atlas do Desenvolvimento Humano no Brasil, PNUD, Ipea, Fundação João Pinheiro, 2003.

Estimativas do autor usando o pacote estatítico stata. 
GRÁFICO 7

Taxas de crescimento da renda per capita municipal

Brasil-1991-2000

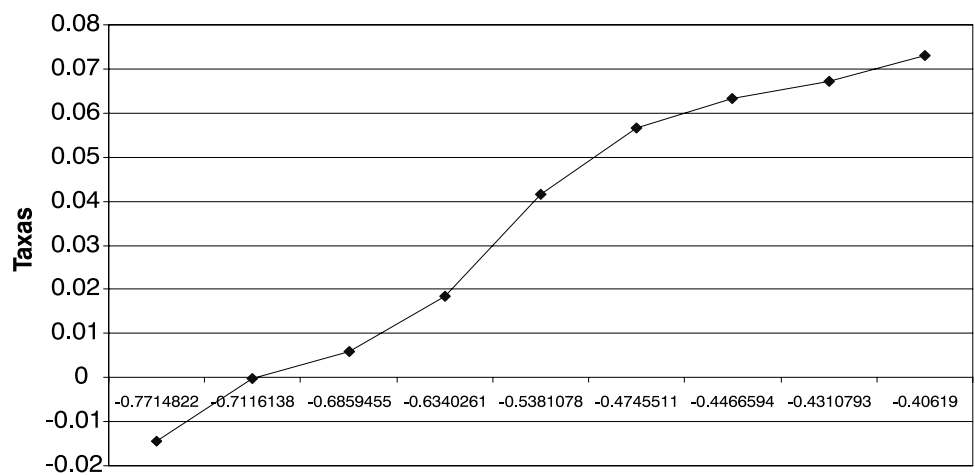

LN da razão PIA/POP municipal em 1991

Fonte: Atlas do Desenvolvimento Humano no Brasil, PNUD, Ipea, Fundação João Pinheiro, 2003.

Estimativas do autor usando o pacote estatítico stata.

GRÁFICO 8

Taxas de crescimento da renda per capita municipal

Brasil-1991-2000

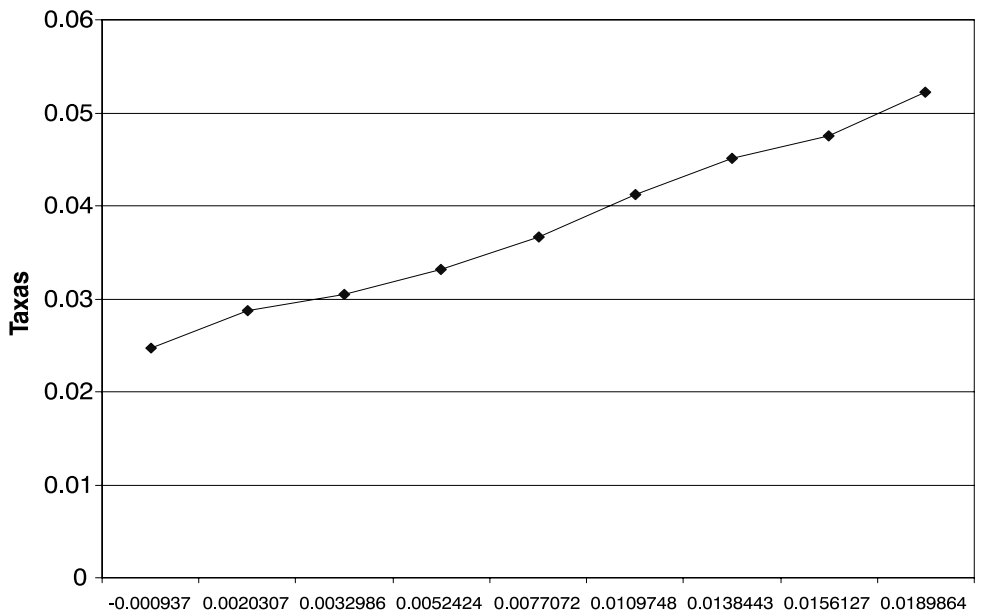

Diferença crescimento PIA e POP municipal 1991-2000

Fonte: Atlas do Desenvolvimento Humano no Brasil, PNUD, Ipea, Fundação João Pinheiro, 2003.

Estimativas do autor usando o pacote estatítico stata.

flutuações razoáveis e esperadas na variável entre os municípios podem causar crescimento a mais na renda per capita de um a dois pontos porcentuais. A expectativa do dividendo demográfico também é confirmada com a variável Difgrpp. 
O Gráfico 8 ilustra este impacto - uma diferença de $0,3 \%$ no crescimento da PIA em relação à população gera um aumento anual na renda per capita de cerca de $3 \%$, isto líquido do efeito Lnpiapop, que é o outro determinante do dividendo demográfico.

Os resultados apresentados demonstram, inequivocamente, a operação do dividendo demográfico nos anos 90 . Se a impressão de vários especialistas foi de que a estagnação econômica não teria viabilizado este dividendo, a evidência econométrica, a partir dos dados municipais, mostra a operação do dividendo, implicando que a estagnação na renda per capita seria muito mais dramática caso o dividendo demográfico não tivesse operado.

Geralmente, os especialistas latinoamericanos criticam a hipótese econômica do dividendo demográfico, ao argumentarem que a mesma seria mais válida para o contexto do leste asiático, sendo que a deterioração do mercado de trabalho na América Latina, com o crescimento do setor informal e da taxa de desemprego aberto nos anos 90 , seria exemplo claro do fracasso da hipótese do dividendo demográfico. Esta peculiaridade dos casos brasileiro e latino-americano, no que tange ao mercado de trabalho, deve ser considerada, mas não pode servir para desqualificar argumentos testáveis.

Uma análise mais profunda das décadas de 80 e 90 pode sugerir pistas sobre falhas institucionais, no mercado de trabalho e em outras instituições, que explicariam a não apropriação total deste dividendo demográfico. Estes componentes estruturais podem ser incorporados na análise do dividendo demográfico, como se verá a seguir. Entretanto, o resultado econométrico disponível no momento já mostra que a participação da população em idade ativa na população total afeta positivamente a renda municipal per capita, a despeito de qualquer dos problemas estruturais anteriormente mencionados.

Mason (2005) define o dividendo demográfico como sendo o resultado do impacto direto do crescimento na razão de suporte econômico, que é definida, grosseiramente, como a razão entre a população em idade ativa e a população total, ou seja, a razão entre produtores e consumidores (esta foi a variável utilizada nas regressões acima). O autor denomina este dividendo demográfico tradicional de "primeiro dividendo demográfico", em contraste a um segundo por ele definido, a ser mencionado posteriormente.

Mensurações do dividendo demográfico fora da esfera dos modelos de crescimento podem utilizar medidas mais refinadas da razão de suporte. No caso do numerador, a população em idade ativa pode ser ponderada pela taxa de atividade por sexo e idade, ou até mesmo por esta taxa e o perfil de rendimentos por idade. No caso do denominador, os consumidores podem ser ponderados por uma taxa de consumo por idade. Uma análise a ser feita no futuro deveria incorporar o papel da educação na razão de suporte econômico, ou seja, em que medida a escolaridade das coortes mais jovens retardaria o problema de declínio na razão de suporte.

Um exercício estilizado, que se baseia em variações na razão de suporte econômico, foi realizado por Turra e Queiroz (2005b), ao analisarem o potencial demográfico do sistema de seguridade social brasileiro. Os autores aplicam a ponderação no numerador pela taxa de participação na PEA por sexo e idade, bem como as taxas de contribuição e de beneficiários no total de dependentes idosos. O exercício permite uma decomposição da razão de suporte, avaliandose o impacto da evasão de contribuição (efeito "evasão") e do aumento na taxa de beneficiários (efeito "generosidade" da constituição). No caso da seguridade social brasileira, a combinação dos efeitos "evasão" e "generosidade" diluiu parte dos benefícios causados pelo dividendo demográfico.

Uma outra possível causa para o primeiro dividendo demográfico é a mudança na taxa agregada de poupança decorrente de um efeito de composição. O perfil poupança-idade atinge os pontos mais 
elevados no auge da população ativa (40 a 50 anos). Assim, um aumento na participação deste segmento no total da população causaria elevação na taxa de poupança. Mason (1988) trata deste aspecto no modelo de taxa de crescimento variável, o qual permite, também, uma mudança no perfil de poupança-idade, como decorrência da queda na razão de dependência familiar.

Mason (2005) define o segundo dividendo demográfico como algo que relaciona o envelhecimento populacional com a riqueza acumulada, o que decorre de efeitos tanto de composição como comportamental. O efeito de composição é causado pelo impacto do envelhecimento da PEA, acarretando maior concentração de riqueza acumulada, por se aproximar da idade de entrada na aposentadoria. O efeito comportamental é provocado pelo impacto dos ganhos de esperança de vida sobre a acumulação de riqueza individual, de forma que o aumento do período em que as necessidades de consumo serão maiores do que a capacidade produtiva demandará maior acumulação de riqueza.

O estoque de riqueza pode ser dividido em dois componentes: transferências (familiares e governamentais); e estoque de capital. Apenas este último componente conta para o segundo dividendo demográfico, por causar o crescimento na renda per capita como decorrência da operação do efeito produtividade do trabalho, o qual, por sua vez, é afetado pelo aumento na relação capital/trabalho, que decorreria do aumento observado no investimento (capital deepening), conforme as identidades (1) e (2), discutidas anteriormente. Reformas institucionais que afetem o papel da família e do Estado nas políticas de transferências intergeracionais, aumentando o papel da capitalização financeira para as alocações intertemporais, aumentam o potencial de coleta do segundo dividendo demográfico.

Sob a ótica da estrutura etária brasileira de momento, reformas institucionais que favoreçam a capitalização ainda permitem uma coleta razoável do segundo dividendo demográfico, sendo esta uma agenda para estudos futuros.

Um ponto central na distinção entre os dois dividendos demográficos, relacionando-a com as identidades (1) e (2), seria que o primeiro dividendo demográfico prioriza o efeito razão de suporte (diferença entre crescimento da PIA e aumento populacional), enquanto o segundo prioriza o efeito produtividade do trabalho, por meio da acumulação de capital.

Uma via para se introduzir a heterogeneidade do mercado de trabalho no debate sobre o primeiro dividendo demográfico seria através da construção de uma razão de suporte com componentes heterogêneos e realistas, assim como Turra e Queiroz (2005b) fizeram para a seguridade social. Neste caso, a heterogeneidade estaria sendo totalmente captada pelos diferenciais da razão de suporte, o que seria feito de forma decomponível.

Outra possibilidade seria tentar desenhar um modelo mais estruturalista, em que parte do dividendo causado pela diferença entre o crescimento dos ocupados e o da população não seria totalmente auferida, uma vez que haveria uma dualidade estrutural no mercado de trabalho. O efeito "dualismo-negativo" do dividendo demográfico pode ser demonstrado num cenário extremo, em que há dois setores de ocupação (formal e informal), com produtividade média dos ocupados no setor formal superior àquela no informal, sendo que ambas as produtividades não variam no tempo, ou seja, o mesmo pressuposto de que a produtividade dos ocupados é constante no tempo, feito no exercício com as identidades (1) e (2), só que, agora, a composição ocupacional varia no tempo, em favor do setor informal, de tal forma que o crescimento dos ocupados ocorre em maior proporção no setor informal do que no formal.

$$
Y / P=\left[\left(Y^{f} / O^{f}\right) \times\left(O^{f} / O\right)+\left(Y^{i} / O^{i}\right) \times\left(O^{i} / O\right)\right] \times\left[\left(O^{f} / O\right) \times(O / P)+\left(O^{i} / O\right) \times(O / P)\right]
$$


Definindo-se:

$\mathrm{Y} / \mathrm{P}=\mathrm{y}=$ renda per capita;

$\mathrm{Y}^{\dagger} / \mathrm{O}^{\dagger}=\mathrm{y}^{\dagger}=$ produtividade no setor formal, assumida constante no tempo;

$\mathrm{Y}^{\mathrm{i}} / \mathrm{O}^{\mathrm{i}}=\mathrm{y}^{\mathrm{i}}=$ produtividade no setor informal, assumida constante no tempo.

Onde, $y^{\dagger}>y^{i}$.

$\mathrm{O}^{\dagger} / \mathrm{O}=\alpha^{\dagger}=$ participação dos ocupados no setor formal;

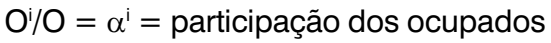
no setor informal;

Onde, $\alpha^{\dagger}+\alpha^{i}=1$.

A identidade (3) pode ser expressa, então, como:

$$
y=\left(\alpha^{f} y^{f}+\alpha^{i} y^{i}\right) \times\left[\left(\alpha^{f}+\alpha^{i}\right) \times(O / P)\right]
$$

Definindo-se $\Delta$ como a variação no tempo para todos os parâmetros de (3'), temse:

$\Delta y=\Delta \alpha^{f} x y^{f}+\Delta \alpha^{i} x y^{i}+\Delta O-\Delta P$

O efeito "dualismo negativo" é gerado pela equação (4), em combinação com as hipóteses do modelo, particularmente a expressão $\left(-\Delta \alpha^{f}=\Delta \alpha^{i}\right)$, ou seja, quando os ganhos porcentuais de ocupados informais correspondem às perdas porcentuais de ocupados formais no total de ocupados. Além disso, como $\mathrm{y}^{\mathfrak{f}}>\mathrm{y}^{\mathrm{i}}$, por definição, fatalmente a soma dos dois primeiros termos da equação (4) será negativa, o que diminui os benefícios do dividendo demográfico medido pelos dois últimos termos da equação, podendo, inclusive, torná-lo negativo.

Outra alteração na discussão sobre o primeiro dividendo demográfico decorre da possibilidade de se incorporar um novo elemento no debate: o possível impacto da estrutura etária na produtividade do trabaIho diretamente. No caso das identidades (1) e (2), discutido anteriormente, esta possibilidade foi descartada por um pressuposto de independência dos dois componentes. Por causa do envelhecimento populacional nos países desenvolvidos, este pressuposto vem sendo questionado por várias vertentes e pode-se aprofundar, na discussão sobre o primeiro dividendo demográfico, a questão sobre um "efeito produtividade".
Prskawetz e Fent (2005) analisam o efeito do envelhecimento populacional sobre a PEA austríaca, do ponto de vista tanto de tamanho como de composição etária. $\mathrm{O}$ impacto, segundo a razão de suporte, seria claramente negativo, devido ao declínio da razão entre produtores e consumidores causado pelo envelhecimento populacional.

Entretanto, os autores estão interessados no efeito da estrutura etária sob a produtividade do trabalho, esta última cotejada no que concerne aos efeitos de uma projeção da PEA, um perfil de produtividade idade para os ocupados e pressupostos sobre o grau de "substitutibilidade" entre os vários segmentos etários dos ocupados. Para melhor detalhar esses pressupostos, os autores focam a análise numa "economia do trabalho pura", desconsiderando, nos modelos de crescimento, a formação de capital e da família.

Os cenários de projeção populacional e da PEA austríaca mostram que o envelhecimento da PEA, medido por sua idade média, pode ser prolongado num contexto de mudanças na taxa de participação na PEA ao longo do processo de envelhecimento populacional. Os autores mostram que o declínio na razão de suporte causado pelo envelhecimento populacional é substancial, e que só um aumento na produtividade poderia compensar este decréscimo.

Eles afirmam que um perfil etário de produtividade-idade horizontal, combinado com perfeita "substitutibilidade" entre ocupados por idade, implica total independência da produtividade do trabalho com relação a tamanho e composição etária da ocupação. Quando os autores relaxam o pressuposto de perfeita "substitutibilidade" entre os ocupados por idade e aplicam uma função de produção CES (constant elasticity of substitution), verificam que o envelhecimento dos ocupados causaria aumento no crescimento da produtividade do trabalho.

Ao compararem o perfil etário de produtividade horizontal com um parabólico por idade e outro declinante por idade, os autores concluem que os dois últimos perfis causam declínio na produtividade total do trabalho, para o caso de perfeita "substitutibilidade", mas a produtividade total do trabalho é 
crescente em todos os casos quando a elasticidade de substituição é meio Este resultado e metodologia são bastante promissores para estudos futuros, com aplicações para o caso brasileiro.

Esses autores revisam as evidências micro e macro a respeito do papel do envelhecimento sobre a produtividade e concluem que as primeiras são ambíguas: o efeito do envelhecimento da força de trabalho pode ser negativo, porque os idosos seriam menos empreendedores ou menos ambiciosos, mas também pode ser positivo, pois uma força de trabalho madura possui estoque de capital humano acumulado maior, principalmente por causa do impacto da experiência e seniority no emprego. Para os autores, o maior problema dos estudos micro é a dificuldade de separar os efeitos de confundimento associados com idade, período, ciclo de vida, processos organizacionais na empresa, etc.

No caso dos estudos macro, Beaudry, Collard e Green (2005) e Beaudry e Collard (2003) analisam o impacto da expansão da PIA sobre a produtividade do trabalho dos países industrializados, na linha dos modelos de crescimento de Solow. Eles concluem que o impacto do crescimento da PIA (15 a 64 anos) não era estatisticamente significante no período 1960-1974, mas passou a ser negativo e importante sobre a produtividade do trabalho entre 1975 e 1997. Os autores sugerem que a introdução de uma mudança tecnológica acarreta adaptações diferentes entre os países, dependendo da taxa de crescimento da sua população adulta. Países com menores taxas se adaptariam mais rápido ao processo de acumulação de capital (capital deepening).

Numa perspectiva que leva a um resultado totalmente diferente, Feyrer (2002) utiliza a estrutura etária como determinante da produtividade, medida como o resíduo na equação de Solow, captando fatores não associados com a acumulação de fatores. Um ponto importante para o papel da estrutura etária no resíduo refere-se ao fato de que a estrutura etária da ocupação é claramente predeterminada. O autor evidencia que o trabalho não está preocupado com a relação entre a
PIA e a população total, como nas estimativas do dividendo demográfico, mas sim, especificamente, com a composição etária da ocupação. A focalização do trabalho na produtividade, em vez do produto, permite que o autor separe o efeito sobre a produtividade daquele sobre a acumulação de fatores. O autor se inspira no papel da experiência, obtido na maioria das estimativas microeconômicas de equações mincerianas de rendimento, para justificar o impacto macro da estrutura etária na produtividade. Ele estima o log da produtividade de resíduo como função de um vetor de variáveis, medido pela proporção de pessoas ocupadas de 10 a 19, 20 a 29, 30 a 39,50 a 59 e 60 a 69 anos, sendo omitido o grupo etário de 40 a 49 anos.

O resultado da regressão estimada para 85 países e sete períodos indica que a curva de produtividade é parabólica com relação à estrutura etária da ocupação, adquirindo valores máximos no grupo etário ocupacional omitido (40-49 anos). O autor contrasta o impacto da estrutura etária na acumulação de fatores (capital e capital humano) com aquele ocorrido na produtividade, chegando à conclusão que este último é dominante.

Concluindo os dois últimos aspectos teóricos aqui revisados, o debate sobre o impacto da estrutura etária pode ser enriquecido pela incorporação dos efeitos sobre a produtividade ocupacional e pela análise específica do mercado de trabalho. A discussão a respeito tanto do efeito "dualismo negativo" quanto daquele referente à produtividade-idade deve ser perseguida em análises futuras.

A agenda de estudos sobre dividendo demográfico deve, portanto, contemplar várias dimensões. Em primeiro lugar, é preciso aprofundar o debate clássico sobre o impacto do dividendo demográfico na renda per capita, no contexto dos modelos clássicos de convergência de renda. Em segundo lugar, devem ser aprofundados os exercícios baseados na razão de suporte, com ênfase naqueles que levam em conta o perfil etário da educação e a relação entre educação e renda numa perspectiva de idade. Em terceiro lugar, é necessário 
incentivar a análise de modelos voltados para o mercado de trabalho, com ênfase nos modelos segmentados e nos estudos da relação entre produtividade e idade. Neste caso último, a análise das tendências observadas na Tabela 8 será importante, apontando para o decréscimo relativo da ocupação para pessoas de 15 a 24 anos, crescimento relativo para aquelas de 45 a 64 anos e constância para o segmento de 25 a 44 anos, caso a tendência da PIA seja um bom indicador para a ocupação.

\section{Transferências intergeracionais na família e no Estado}

Em termos gerais, as relações entre gerações podem se dar por intermédio do Estado ou da família, mecanismos institucionais que viabilizam a troca de recursos no tempo. O mercado é o terceiro mecanismo de alocação intertemporal de recursos, servindo como alternativa aos dois mecanismos institucionais mencionados. Restrições de créditos, assimetrias de informação, risco moral, miopia intertemporal, entre outros aspectos, acabam afetando a eficácia do mercado para substituir a família e o Estado. Família, Estado e mercado configuram o que a literatura convencionalmente chama de três pilares da geração de bem-estar social. Como, no caso brasileiro, as restrições de crédito, imperfeições na posse de ativos que sirvam de colaterais para empréstimos e uma eventual elevada taxa de desconto intertemporal são restritivas ao papel do mercado, a presente análise estará centrada nas relações entre família e Estado, vistas como mecanismos de geração das transferências intergeracionais.

Família é um tipo de instituição que viabiliza uma série de trocas entre os indivíduos que são seus membros, envolvendo custos, benefícios, altruísmo, cooperação, conflito, externalidades, identidade, baixa assimetria de informação, entre outros aspectos. A economia da família e a do domicílio possuem grande interseção, embora claramente a primeira seja mais ampla, por permitir relações intergeracionais que não exijam co-residência, ou até mesmo por permitir relações dinásticas (que perpetuam a família por mais de três gerações). Foge aos propósitos deste trabalho discutir os aspectos micro das relações familiares, uma temática relevante, em que é tratada uma série de questões importantes, como, por exemplo, a relação entre conflito e cooperação, questões de gênero, a alocação intradomiciliar do consumo, herança, questões entre gerações, a transição do jovem para a vida adulta, o divórcio e separação, etc. Os aspectos micro só serão mencionados aqui à medida que ajudem a descrever o papel da família como mecanismo de transferência intergeracional.

Talvez o melhor caso para se discutir o papel da família na transferência intergeracional de recursos seja o debate sobre os determinantes da educação dos filhos. Este caso é importante porque praticamente todas as teorias na área de ciências humanas reservam um papel crucial para a família, na determinação da educação tanto formal quanto informal dos filhos. A educação é importante também porque os serviços demandados pela família são prestados ou pelo Estado (mediante transferências governamentais e ensino gratuito) ou pelo mercado, trazendo à baila a interação da família com os dois outros pilares.

Um outro exemplo clássico de serviços intergeracionais prestados pela família é o caso da segurança na velhice, em que membros familiares cuidam de seus idosos e provêm transferências de renda intrafamiliares. Todo demógrafo já ouviu falar, alguma vez, da hipótese da segurança na velhice como importante determinante da alta fecundidade em sociedades tradicionais. Estes são dois exemplos interessantes porque enfatizam a relação dos membros familiares com os dois extremos da pirâmide etária - as crianças e os idosos.

O modelo de Becker e Tomes (1986) é ilustrativo ao mostrar um grande problema de ineficiência por parte das famílias, no que tange ao investimento em capital humano. Neste modelo, as famílias investem no capital humano dos seus filhos, mas também transferem recursos econômicos para eles - por exemplo, através de 
herança. Como os filhos possuem habilidades de aprendizado diferentes, a combinação entre herança e investimento em educação não será igual entre eles, com a família agindo de maneira compensatória. O problema de ineficiência apontado pelos autores surge no caso das famílias pobres, uma vez que a limitação orçamentária e as restrições de crédito impedirão as transferências de herança (configurando uma "solução de canto") e, pior ainda, a escolha ótima de educação será ineficiente, no sentido de que a taxa de retorno para investimento em educação será maior do que a taxa de retorno para aplicações financeiras no mercado.

Esta ineficiência quer dizer que as famílias pobres investiriam mais nos filhos se não tivessem limitações de renda e de crédito. Esta seria uma das explicações para a robusta correlação negativa observada entre a renda domiciliar per capita e o desempenho escolar das crianças residentes no domicílio.

Uma explicação para que o Estado efetue transferências universais na área de educação é a hipótese da eficiência, ou seja, a transferência intergeracional para as crianças, por intermédio dos gastos em educação, levaria a um melhoramento de Pareto, uma vez que reduziria o investimento ineficiente em capital humano por parte das famílias com restrição orçamentária alta e solução de canto (famílias pobres). Um programa de transferência direta de renda como, por exemplo, o Bolsa Família poderia também melhorar esta eficiência. Becker e Murphy (1988), no trabalho clássico Família e Estado, utilizam esta lógica sobre a ineficiência familiar na esfera da educação, combinada com os problemas de provisão de segurança na velhice, para justificar um pacto intergeracional de eficiência efetuado pelo Estado por parte das transferências governamentais em educação e seguridade social. No caso de um modelo de três gerações, os contribuintes ativos financiariam os gastos públicos educacionais na base da pirâmide, com a expectativa de que a taxa de retorno do investimento em capital humano, ao ser materializada nas folhas de salários das antigas crianças, quando estas entrarem no mercado de trabalho, seria suficiente para pagar a aposentadoria dos antigos contribuintes ativos que, agora, acabariam de se tornar aposentados. Esta hipótese sugere que a seguridade social baseada em transferências governamentais, no regime de repartição simples, é uma resposta eficiente ao problema de investimento em educação no âmbito da família. Neste caso, não há conflito entre gastos com seguridade social e outros programas sociais, pois o primeiro não reduz os demais (ausência de crowding out ${ }^{7}$ dos outros programas pela seguridade social). Também não faz sentido falar de redistribuição de recursos entre coortes, dos jovens para os idosos.

A argumentação de Becker e Murphy (1988) não é a única explicação econômica baseada na hipótese da eficiência, mas sim a explicação de eficiência correlacionada com investimentos em capital humano e transferências intergeracionais. Mulligan e Sala-i-Martin (1999b) citam oito teorias de ineficiência de mercado, em que a seguridade social é considerada uma maneira para atingir eficiência: ótima redistribuição ou divisão de riscos; espraiamento de capital humano; ótimo seguro de aposentadoria; prodigalidade paternal; extração keynesiana da poupança; ótimo seguro de longevidade; retorno ao capital humano; e economias de escala administrativas. Além do trabalho de Becker e Murphy, os autores afirmam que Pogue e Sgontz (apud Mulligan e Sala-i-Martin, 1999b) também formularam a hipótese da eficiência no caso do retorno ao capital humano.

Mulligan e Sala-i-Martin (1999a) dividem as teorias positivas de seguridade social em dois grupos: as de eficiência e as políticas. As primeiras foram discutidas anteriormente, enquanto as teorias de

\footnotetext{
${ }^{7}$ Esta expressão significa uma competição por recursos que reduz a participação dos demais; no contexto, significaria que a previdência drenaria os recursos dos demais programas.
} 
políticas consideram a seguridade social o resultado de uma disputa política distributiva. Os cidadãos se articulam em dois grupos políticos, com o intuito de apropriar os recursos do Estado, sendo que um grupo será o vencedor. Se a teoria prevê que os idosos representam um grupo e eles ganham a disputa, então esta é uma teoria política de seguridade social. Como conseqüência da redistribuição dos recursos dos jovens para os idosos, os gastos em seguridade social reduzem os demais gastos sociais (crowding out dos outros programas pela seguridade social). Os autores dividem as teorias políticas em dois grupos: as de voto racional da maioria e as de grupos de pressão.

As teorias do voto racional da maioria entendem a seguridade social como o prêmio final de uma luta. Quando aplicadas para regimes democráticos, estas teorias prevêem os resultados de uma eleição na qual os grupos votam no seu interesse próprio. Uma primeira versão destas teorias, formulada por Tabellini (apud Mulligan e Sala-i-Martin, 1999a), sugere que os idosos fazem uma coalizão com outro grupo de eleitores (os pobres), para vencer os eleitores jovens e ricos. Mulligan e Sala-i-Martin concluem que o modelo tem problemas para explicitar os ganhos dos idosos e dos jovens pobres na coalizão, além de não gerar uma série de predições que explicariam fatos estilizados da seguridade social.

Uma segunda versão sugere uma eleição feita uma vez e para sempre, realizando uma coalizão com os grupos etários intermediários. A idéia seria de que o programa, apesar de afetar os interesses imediatos dos grupos etários intermediários, beneficia-os no longo prazo, pois, em algum momento, eles se tornam idosos. Mulligan e Sala-i-Martin concluem que o modelo tem os mesmos problemas da versão anterior, além de apresentar dificuldades para explicar votos num período posterior, quando uma suspensão temporária do programa poderia ser votada por alguns grupos etários de interesses distintos dos idosos.

$\mathrm{Na}$ linha dos modelos de grupos de pressão, Mulligan e Sala-i-Martin desenvolvem um modelo de competição política entre jovens e idosos, denominado "competição política intensiva em tempo", uma vez que os grupos, cujos membros trabalham menos, terão mais tempo para defender seus interesses, como o de aposentados. O modelo mostra como os idosos enfrentam menos resistência para o sucesso político do que os grupos de baixo salário, uma vez que todos os grupos serão idosos um dia, enquanto a mobilidade entre os grupos de baixo e alto salário não é grande.

Um outro modelo de grupos de pressão é o de proteção do contribuinte, desenvolvido por Becker e Mulligan (apud Mulligan e Sala-i-Martin, 1999a). O modelo afirma que impostos e subsídios ineficientes são formas de reduzir o tamanho do governo, ao desestimularem o lobby dos grupos de pressão. O modelo assume que os jovens e os idosos fazem pressão política no que concerne à implementação de um programa de seguridade social. Os impostos pagos pelos jovens equivalem aos benefícios recebido pelos idosos, determinando o tamanho do programa de seguridade social. A pressão de cada um dos dois grupos depende do volume de recursos gastos por eles com o exercício da pressão política.

O modelo prevê que os benefícios per capita dos idosos serão substanciais, mesmo quando a fração de idosos na população total for pequena. Os contribuintes favorecem distorções no sistema de tributo para limitar o tamanho do programa de seguridade social.

Mulligan e Sala-i-Martin (1999a e 1999b) fazem uma revisão mais economicista, mesmo quando falam de teorias políticas, concluindo que estas se ajustam mais aos fatos estilizados do que as teorias de eficiência, o mesmo ocorrendo no que tange às possibilidades de ajustes na seguridade social, com vistas a reformas do sistema.

$\mathrm{Na}$ esfera demográfica, o seminal Presidential addres, de Samuel Preston, como presidente da Population Association of America (PAA), em 1984, menciona o conflito entre idosos e crianças. Ele usa como um dos argumentos centrais o baixo 
poder de votos e lobby por parte das crianças, em contraste com o alto poder de mobilização dos idosos (gray power), nos Estados Unidos. Segundo o autor, estas mudanças geracionais estariam afetando a distribuição de recursos públicos no país.

As diferenças principais entre as teorias de eficiência e as teorias políticas podem ser sintetizadas, no sentido de ajudar no mapeamento do papel heurístico de cada teoria para análises do caso brasileiro. As teorias de eficiência são aqui representadas pelo modelo de Becker e Murphy (1988), embora outros modelos de eficiência de gerações superpostas também explicam o mesmo tipo de resultado sinérgico entre educação e pensões (Boldrin e Montes, 2004).

No caso das relações entre políticas de educação e seguridade social, as teorias de eficiência indicam a ausência de conflitos intergeracionais, sendo que o sistema de seguridade social por repartição simples viabiliza as restrições de crédito dos jovens e garante o pagamento futuro das pensões e aposentadorias. Nesta teoria, não há crowding out de gastos educacionais motivados pelo crescimento da seguridade social, uma vez que este aumento depende do retorno dos investimentos em educação pública. Finalmente, nesta teoria, não há necessidade de reforma do sistema de seguridade social.

Nas teorias políticas, espera-se mais ou menos o oposto. Mesmo como exemplificado no caso de Preston (1984), há conflitos intergeracionais, crowding out dos gastos educacionais decorrentes do crescimento da seguridade social e necessidade de reforma do sistema de seguridade social.

A reflexão sobre as relações intergeracionais no contexto brasileiro deverá levar em conta estes dois paradigmas opostos, com um foco privilegiado na questão entre educação e seguridade social.

Uma vertente da contabilidade nacional de transferência, que incorpora o componente demográfico na análise das transferências intergeracionais, consiste numa metodologia desenvolvida por Ronald Lee e colaboradores (Mason, Lee, Tung, Lai e Miller, 2005). A adoção deste arcabouço independe da escolha de um modelo teórico de eficiência ou de um modelo político de transferências intergeracionais, no contexto da discussão anterior. Como o próprio nome diz, o objetivo é medir o conjunto de transferências ou realocações entre os diversos grupos etários.

Lee e colaboradores aplicam a contabilidade de transferências públicas para o caso das gerações norte-americanas nascidas entre 1850 e 2090 (Bommier, Lee, Miller, Zuber, 2005). A análise combinada dos benefícios líquidos de transferências para os jovens, via gastos com educação, e de transferência para os idosos, via gastos com seguridade social e saúde (medicare), é medida para as diferentes gerações. $O$ valor presente do benefício líquido no nascimento, obtido para as três transferências governamentais, é positivo para a maioria das gerações observadas entre 1850 e 2050.

As coortes nascidas entre 1850 e 1879 apresentaram valor presente líquido negativo, devido à expansão do sistema público de educação nos Estados Unidos. As coortes nascidas entre 1930 e 1947 também experimentaram valor presente líquido negativo, fato igualmente causado por nova expansão do sistema educacional. A coorte de 1914 recebeu o maior retorno, equivalente a cerca $5,3 \%$ do seu rendimento de ciclo de vida, em função do início do sistema de seguridade social. As coortes de 1992 e 1993 também tiveram um pico de retorno equivalente a $5,8 \%$ do seu rendimento de ciclo de vida, neste caso provocado pelo retorno do sistema educacional, viabilizado pelo financiamento das gerações prévias.

Os autores concluem que o financiamento do sistema público de educação é caro, apesar de o capital humano ser um dos principais determinantes do crescimento econômico. De qualquer forma, os retornos calculados para as coortes são consistentes com a hipótese de eficiência de Becker e Murphy, a despeito de os valores sugerirem que as transferências para os idosos não sejam apenas para compensar os investimentos feitos em educação, pois chegam a atingir valores bem maiores. 
Passando da discussão teórica para o caso brasileiro, a contabilidade geracional no Brasil é apresentada em Turra (2000), que usa perfis etários de utilização de serviços públicos e de renda e de consumo por idade, gerados a partir da Pesquisa de Padrão de Vida (PPV - 1996-1997), realizada pelo IBGE, em combinação com dados agregados sobre gastos sociais nas três esferas públicas. A atribuição de valores per capita (em reais de dezembro de 1996), por idade, permitiu a montagem final da contabilidade geracional.

A elaboração do diagrama de setas, representando a direção das transferências intergeracionais, é dada pela diferença entre a idade de pagamento (base da seta), a idade de recebimento (ponta da seta), o fluxo anual per capita (largura da seta) e a riqueza anual per capita (área da seta). As despesas com INSS, previdência dos servidores e saúde favorecem aos idosos, enquanto os gastos com educação favorecem crianças e jovens. O conjunto das transferências públicas é, inegavelmente, favorável aos idosos. As transferências domiciliares são favoráveis às crianças e aos jovens, enquanto as intradomiciliares são maiores e associadas à criação dos filhos. As interdomiciliares referem-se às heranças. O conjunto das transferências públicas (favorável aos idosos) contrasta com o das transferências domiciliares (favorável às crianças e jovens). Considerando-se a riqueza anual per capita, as famílias mais que compensam as transferências públicas favoráveis aos idosos, ao investirem na criação dos filhos (consumo, educação, etc.).

O importante trabalho de Turra e Queiroz (2005a) estende a discussão anterior para uma análise que incorpora as desigualdades sociais, medidas por quatro estratos de escolaridade do responsável pelo domićlio. O estudo está centrado nas transferências dos gastos governamentais com educação, saúde e seguridade social, além de descrever as transferências intervivos (inter e intra domiciliares).

A análise baseia-se na perspectiva de diferenciais cross section, ou seja, de período. Os próprios autores reconhecem, no artigo, que a limitação da base de dados impediu um estudo adequado de outras hipóteses, particularmente a análise histórica da formação do sistema de transferências públicas no Brasil. No caso dos gastos governamentais com educação, o valor per capita é maior para o segmento com famílias no estrato com maior escolaridade (nível superior) do que nos demais, sendo que a transferência ocorre em idades mais avançadas (20 a 29 anos), o que contrasta com as demais classes, em que o peso é maior no grupo de 10 a 19 anos. Isto ocorre porque esta transferência está mais associada ao ensino superior.

Quando os gastos com educação são padronizados pelo nível de consumo de cada classe de escolaridade do responsável, a participação dos gastos em educação é maior para as classes menos favorecidas e no ensino básico. Os gastos com saúde apresentam maiores valores para as idades mais avançadas, principalmente no caso da classe social menos favorecida. Segundo o perfil etário, o gasto com seguridade social também é crescente à medida que aumenta a idade, embora indique uma certa precocidade na coleta do benefício previdenciário. Quando padronizados pelo consumo, os diferenciais por classe são relativamente menos importantes neste grupo de gastos governamentais. Já as transferências privadas propiciam as crianças, principalmente no caso das duas classes mais favorecidas.

Turra e Queiroz (2005a) concluem que as transferências governamentais favorecem menos as crianças pobres, uma vez que as transferências para os idosos são menos diferenciadas por classes de educação do que aquelas para as crianças. Este resultado traz para o debate a ligação entre as transferências intergeracionais e a focalização de políticas sociais no combate à pobreza.

Claramente, as políticas de transferências governamentais estão aliviando mais a pobreza dos idosos do que a das crianças. Os autores colocam uma explicação, inspirada na hipótese de Preston, que neste trabalho é classificada como teoria política, em contraste com a teoria de eficiência. Eles 
sugerem quatro grupos de pressão, marcados pelas divisões geracional (adultos e crianças) e de classes (alta e baixa). As crianças de classe alta não têm interesse no jogo, pois seus pais transferem recursos na esfera privada. Os adultos de classe alta têm interesse na seguridade social, e buscam aliança com os adultos de classe baixa. Como as crianças de classe baixa não têm poder de voto, a coalizão entre adultos de ambas as classes para favorecer políticas que beneficiem os idosos parece robusta.

Barros e Carvalho (2003) argumentam que os programas sociais brasileiros são mal focalizados, uma vez que falham em repartir os recursos com os mais pobres. Os autores utilizam o viés intergeracional para contrastar os problemas de focalização, comparando a previdência rural e o BPC (Benefício de Prestação Continuada) com o programa Bolsa-Escola, em vigor até 2003. Os dados mostram que a redução da pobreza, em decorrência dos programas, ocorre mais fortemente nas idades mais avançadas do que nas mais jovens. Estes resultados são compatíveis com a explicação sugerida por Tuma e Queiroz.

A explicação ou hipótese sugerida anteriormente por Turra e Queiroz (2005a) deve ser considerada uma forte possibilidade. Entretanto, à luz do debate teórico anteriormente revisado, ainda não é possível descartar considerações acerca da hipótese da eficiência em capital humano, aplicada ao contexto brasileiro. A discussão da hipótese da eficiência requer aplicação de uma perspectiva histórica, sendo que a análise das transferências, na perspectiva de coorte, é limitada pela disponibilidade dos dados no Brasil. Esta é, talvez, a questão mais importante para a agenda de futuras pesquisas na área de transferências intergeracionais. A Nota de pesquisa, de Turra e Queiroz (no prelo), aponta, precisamente, para a necessidade do contraste entre estas duas hipóteses.

Uma inspeção inicial e superficial nas estatísticas históricas de gastos públicos pode fornecer pistas sobre os problemas encontrados pela abordagem da eficiência no Brasil, em contraste com a experiência americana, reportada por Lee e colaboradores. No caso americano, a revolução educacional antecede a implantação da seguridade social, sendo que o processo tem início em meados do século XIX. Neste caso, a hipótese da eficiência de Becker e Murphy ocorre na gênese das transferências intergeracionais governamentais. No caso brasileiro, a gênese dos gastos sociais é relativamente recente, ocorrida apenas na segunda metade do século XX.

Para os gastos públicos com previdência social, Andrade (1999) apresenta excelente reconstituição histórica. Criada pela Lei Elói Chaves em 1923, a previdência brasileira só foi unificada no pósguerra, passando por uma série de regulamentações nas décadas seguintes, até a reforma constitucional de 1988, que estabeleceu o contexto institucional atual da seguridade social, com a ampliação dos benefícios e da cobertura, além dos problemas de equacionamento do seu financiamento.

A série histórica elaborada pela autora mostra que a despesa previdenciária corrente é inferior à receita corrente desde a unificação até meados dos anos 60 , passando por um período de relativo equilíbrio, sendo superavitária novamente na década de 80 , voltando a uma situação de equilíbrio e em seguida de déficit a partir dos anos 90. Este período de implantação e expansão da previdência social unificada marca uma grande virtuosidade, dada pela elevada razão de suporte. ${ }^{8}$

O exercício de capitalização dos saldos positivos do sistema previdenciário, entre 1945 e 1980, chega a valores exorbitantes, segundo cálculos de Andrade (1999). Cabe, então, estabelecer a natureza do pacto de finanças públicas, realizado historicamente, tendo em vista esta enorme arrecadação pública, assim como as expectativas da hipótese de eficiência no capital humano.

\footnotetext{
${ }^{8}$ Razão de suporte é definida na parte referente ao dividendo demográfico e, em termos previdenciários, quer dizer a razão entre arrecadação dos contribuintes e pagamento dos benefícios.
} 
A história da educação no Brasil é bem menos auspiciosa do que a da previdência social, o que se reflete nos péssimos indicadores educacionais prevalentes na maior parte do século XX. Um marco regulador na política educacional é a determinação do ensino primário obrigatório (até quatro anos de estudo completos), na Constituição de 1946, cabendo à União o poder de legislar sobre esta área. ${ }^{9}$

Em 1953, o Ministério da Saúde foi criado e se separou da pasta, sendo implantado, então, o Ministério da Educação e Cultura. Em 1971, regulamentou-se o ensino de primeiro e segundo graus, aumentando a obrigatoriedade escolar para oito anos. Em 1982, foi tentada a primeira experiência de ensino em tempo integral no país, no Estado do Rio de Janeiro, por iniciativa de Darcy Ribeiro, visando atender até mil crianças em dois turnos de atividades nos chamados Cieps (Centros Integrados de Educação Pública). Esta iniciativa precedeu a universalização da matrícula e do atendimento escolar, sendo prematura e, por isso mesmo, criticada por competidores políticos. Em 1983, foi aprovada a vinculação constitucional de recursos para educação (Emenda João Calmon), objetivando a manutenção e desenvolvimento do ensino em patamares mínimos de investimento público.

O projeto de lei da nova Lei de Diretrizes e Bases da Educação (LDB) foi encaminhado à Câmara Federal em 1988, mas só foi sancionado em 1996. Em 1995, o governo federal enviou uma emenda constitucional e criou o Fundef, que se tornou instrumento fundamental para a busca da universalização do atendimento escolar. Finalmente, em 2001, o Programa Bolsa-Escola, federal, foi criado por Medida Provisória e aprovado pelo Congresso Nacional.

Um documento do Banco Mundial (2003) afirma que a LDB e o Fundef foram fundamentais para estabelecer uma divisão de responsabilidades nas diversas esferas de governo. As administrações municipais seriam responsáveis pela educação infantil, os governos estaduais pelo ensino médio e ambos deveriam cooperar entre si na responsabilidade pelo ensino fundamental. Houve aumento marcante nos gastos com educação, que passaram de $4,2 \%$ do PIB, em 1995, para 5,6\%, em 2000. Um aspecto interessante no mecanismo de operação do Fundef é o fato deste Fundo arrecadar recursos oriundos dos governos estaduais e municipais e depois redistribuir de acordo com a matrícula efetiva em cada esfera governamental, gerando um incentivo para a expansão da cobertura escolar.

Do ponto de vista de indicadores escolares, os dados dos censos demográficos mostram crescimento na taxa de atendimento das pessoas de 7 a 14 anos (matrículas, desta faixa etária, em todos os níveis de ensino, divididas pela população total na mesma faixa etária), que passou de pouco mais de $60 \%$, em 1970 , para $68 \%$, em 1980, chegando a $80 \%$, em 1991, e a quase $95 \%$, em 2000. Os dados das PNADs do IBGE mostram uma evolução ainda mais radical da taxa de atendimento escolar do grupo de 7 a 14 anos, passando de cerca de $78 \%$, em 1981 , para $82 \%$, em 1991 , e atingindo $97 \%$, em 2002.

Estes dados apontam para uma virtual universalização do atendimento escolar na década de 90. A universalização da matrícula escolar é só o início da revolução necessária para o investimento em capital humano. É preciso ampliar a cobertura no ensino médio e melhorar a qualidade do ensino, não só reduzindo a defasagem entre idade e série, mas também melhorando a proficiência escolar, sendo ambos indicadores de qualidade da educação.

O trabalho de Sochaczewski (2003) sobre as finanças públicas brasileiras no século XX mostra que, desde 1930 , os

\footnotetext{
${ }^{9}$ Peço desculpas por uma nota pessoal para o caso da educação. Ironicamente, duas gerações da minha família estiveram envolvidas com o processo. Meu avô trabalhou com o ministro Clemente Mariani Bittencourt, no governo Dutra, tendo sido ministro interino por dois meses, em 1950. Meu pai foi presidente da Campanha Nacional dos Educandários Gratuitos em Minas Gerais, no período entre 1956 e 1958. Este era um movimento voluntário da sociedade civil voltado para a criação de ginásios (o que, atualmente, equivale ao ensino de 5 a à 8 a séries do ensino fundamental) gratuitos, com o intuito de cobrir as deficiências da política governamental na área de educação.
} 
gastos com infra-estrutura foram superiores a $2 \%$ do PIB - mais especificamente entre 1930 e 1940, 1956 e 1964, 1968 e 1970 e de 1986 a 1988. Estes gastos só se tornaram inferiores a 1\% do PIB após 1990 . Três picos do gasto com infra-estrutura, em anos simples, merecem destaque: cerca de $2,7 \%$ do PIB em 1957; 3\% em 1963; e 2,6\% em 1968-1969. Já os gastos sociais foram inferiores a $1 \%$ do PIB até 1950 , girando em torno de $1 \%$ até 1968 , declinando novamente até 1974, recuperando posição para o patamar de $1 \%$ até 1984 e depois subindo de $1 \%$ para $2 \%$, entre 1985 e 1990 .

No período de 1976 a 1988, os gastos com infra-estrutura e sociais evoluíram no mesmo patamar e em idêntico ritmo de crescimento. Na década de 90 , os gastos sociais explodiram, até chegarem a $6 \%$ do PIB em 1994, enquanto aqueles realizados com infra-estrutura despencaram para cerca de $0,2 \%$ do PIB neste período. Entre 1996 e 2000, os primeiros estabilizaram-se pouco acima de $3 \%$ do PIB e os referentes à infra-estrutura permaneceram no patamar de $0,2 \%$ do PIB. ${ }^{10}$

Voltando ao debate teórico acerca do contraste entre a hipótese do conflito político intergeracional e a da eficiência entre os gastos com educação e seguridade social, a pequena revisão apresentada anteriormente, sobre as políticas sociais clássicas, sugere que a política de transferências governamentais brasileiras na área social remonta, no máximo, ao período pós-guerra. Também fica claro que os gastos de transferências previdenciárias e com saúde precederam as despesas com educação. Neste sentido, a gênese da política social universal brasileira não apresenta quadro compatível com a hipótese da eficiência em gastos com capital humano.

Resta saber se o modelo político implantado no pós-guerra era simplesmente motivado por um pacto dos idosos ricos e pobres contra os jovens pobres, ou se havia outros componentes no processo. A série de gastos com infra-estrutura mencionada anteriormente oferece uma pista na direção de um pacto de complementaridade entre investimento em capital físico, via infraestrutura, e transferência futura de recursos para os idosos. A realocação de ativos em infra-estrutura pública proporciona uma perspectiva de transferência de recursos presentes para recursos futuros, com uma determinada taxa de retorno, sendo os recursos presentes gerados com a expansão do sistema de previdência social, tal qual discutido por Andrade (1999).

Nos moldes dos anos 50 e 60, o retorno mais rápido ao investimento em infraestrutura (capital fixo) ${ }^{11}$ constituiu opção mais atrativa do que a parceria entre educação e seguridade social propugnada pela hipótese da eficiência em capital humano. Se este arranjo, por um lado, viabilizou, historicamente, o chamado milagre econômico brasileiro, por outro, aumentou a desigualdade de rendimentos, ao criar uma demanda por capital humano sem ter viabilizado sua oferta, conforme foi bem descrito por Carlos Langoni na época. O resultado foi um aumento no prêmio à educação, o qual que tem sido uma marca da desigualdade de rendimentos da PEA brasileira.

É justamente a alta histórica taxa de retorno à educação no Brasil que torna o modelo de Becker e Murphy, da eficiência em capital humano, um paradigma ainda relevante para a política pública no Brasil. Por um lado, as evidências empíricas micro confirmam a existência de restrições de crédito por parte das famílias pobres brasileiras, redundando numa ineficiência em termos de escolaridade. O programa Bolsa-Escola, anteriormente mencionado, e a sua mais recente transferência para o Bolsa-Família refletem um esforço de políticas públicas para aliviar esta restrição

\footnotetext{
${ }^{10}$ Os gastos medidos em porcentagem do PIB podem estar sujeitos a controvérsias e questões metodológicas. A menção aqui é apenas ilustrativa, com o intuito de mostrar flutuações e tendências que seriam captadas pelo fato de se estar usando a mesma metodologia.

${ }^{11}$ Por uma questão de retórica, enfatiza-se o papel da infra-estrutura na produtividade econômica, mas é óbvio que a mesma também impactou outros aspectos do capital humano, como a saúde: por exemplo, os efeitos do investimento em água e esgoto na queda da mortalidade.
} 
de crédito. Por outro lado, o novo patamar recente de gastos sociais como porcentagem do PIB, descrito anteriormente, indica um esgotamento do financiamento da previdência social no país, algo que ocorre num momento especial, quando parte do potencial gerado pelo dividendo demográfico já foi desperdiçado. $\mathrm{O}$ crescimento e o aumento da eficiência no gasto educacional, observados no final dos anos 90 , são positivos, mas provavelmente ainda não suficientes. Tendo em vista as relações inter-geracionais no século XXI, no contexto do debate sobre o dividendo demográfico aqui realizado, o arranjo político nos moldes da hipótese da eficiência em capital humano parece ser não somente um melhoramento de Pareto, em termos de eficiência, mas também a melhor saída para elevar a razão de suporte econômico. A solução deste dilema dependerá do teste da realidade, indicando se a cooperação da eficiência é politicamente mais viável do que a aliança do modelo de conflito intergeracional.

Se o modelo de Becker e Murphy prevalecer no caso brasileiro, este ficará marcado como um exemplo de modelo em que a implantação da seguridade social e sua posterior universalização precedem a revolução na educação, gerando um aumento na desigualdade intra e intergeracional. $O$ pacto posterior, que ainda não é realidade, visando salvar a crise na previdência social por intermédio do aumento no investimento público em capital humano, pode viabilizar uma maior eqüidade intra e intergeracional.

\section{Comentários finais: à guisa de conclusão}

A falta de espaço fez com que uma série de tópicos não fosse abordada. A opção pela relação da dinâmica demográfica com as conseqüências macro, associadas à estrutura etária, explica parte destas omissões, tais como a ausência de discussão sobre o comportamento micro da família, principalmente no que tange ao processo de tomada de decisões de seus membros, contrastando conflito com cooperação. Este contraste aplica-se tanto a aspectos de gênero quanto a conflitos geracionais, nas relações entre pais e filhos.

A respeito desta complexa temática, cumpre destacar o excelente capítulo de Goldani (2004), no volume sobre idosos, organizado por Camarano (2004). A autora questiona a dicotomização macro e micro das esferas sociais. Segundo ela, o âmbito micro pressupõe uma família solidária entre seus membros, com predominância do elemento feminino na provisão de serviços domiciliares. O questionamento desta visão solidária não é privilégio daqueles que adotam uma perspectiva de gênero, a partir de abordagens sociológicas.

Também os economistas admitem, atualmente, que os membros familiares possuem conflitos de alocação de recursos, no interior do domicílio (intrahousehold allocations), que são distribuídos de acordo com o poder de barganha de seus membros. Há vasta documentação, em trabalhos no âmbito do Banco Mundial, advogando que as transferências monetárias e de outros ativos (título de propriedade de terrenos ou casas) sejam efetuadas para as mulheres (na maioria dos casos, mães), que seriam mais comprometidas com transferências e alocações familiares voltadas para as crianças.

No caso do modelo econômico de família, além da ausência do debate sobre cooperação e conflito, faltou uma discussão a respeito do conceito de altruísmo familiar, em que o teorema do Rotten Kid ${ }^{12}$ coloca um papel fundamental. Não foi discutido o paradigma da equivalência ricardiana de Barro (1974), que levanta a possibilidade da família com preocupação dinástica de compensar prováveis erros de transferência realizados pelo governo.

A proposta de Barro é discutida no contexto da relação entre déficit público, riqueza e poupança familiar. No caso de políticas de transferência, como a aposentadoria

\footnotetext{
${ }^{12}$ O teorema do Rrotten Kkid diz que um filho egoísta e pouco cooperativo não é capaz de agir contra os membros familiares, desde que seu pai ou algum outro membro da família seja altruísta.
} 
rural, estratégias compensatórias familiares, atraindo os netos para o consumo de transferências intradomiciliares, poderiam ser interpretadas no contexto da hipótese de Barro.

O debate sobre políticas públicas e transferência de renda centrou na relação entre gastos com educação e com seguridade social. Como ambas as políticas são de cunho universal, o debate entre focalização e universalização de políticas públicas não foi realizado. Considerandose o conflito intergeracional de forma stricto sensu, mesmo estas políticas envolvem uma focalização por idade. Tal ponto mostra quão relativo este debate pode ser. Ao perguntar "qual Estado de Bem-Estar", Goldani (2004) associa a discussão sobre conflito intergeracional àquele entre focalização e universalização das políticas públicas.

Foge aos propósitos desta conclusão reproduzir aqui o debate. Não se discute que a universalização de políticas sociais clássicas, como educação, saúde e previdência, deve ser almejada. Há fatores que limitam a progressividade da igualdade de provisão governamental oriunda de uma universalização levada a ferro e fogo - por exemplo, o passado de extrema desigualdade da sociedade brasileira, que remonta a uma nação que esteve entre as últimas a banir a escravidão, ou os limites de inserção ocupacional de boa qualidade, ligados a problemas de demanda e de oferta no mercado de trabalho. É este o contexto que justifica políticas focalizadas de transferências de renda, voltadas para o atendimento de segmentos populacionais abaixo da linha de pobreza, assim como as políticas de cotas para pobres e negros.

Um exemplo de política focalizada, no contexto da universalização gerada pela política educacional, é o caso do programa Bolsa-Escola e da sua versão atualizada no Bolsa-Família. A discussão no item anterior mostra que as restrições de crédito se limitam ao segmento de famílias pobres, o que leva a uma ineficiência na demanda por escolaridade das famílias mais pobres, fato comprovado pelo importante papel da renda per capita domiciliar na determinação da escolaridade das crianças e jovens vivendo nos domicílios. Sendo assim, a mera alocação de recursos públicos para a oferta de escolas e professores pode ser insuficiente para gerar o desempenho escolar desejado. No caso, a transferência de renda, condicionada ao comportamento familiar, é instrumento importante de focalização. Outro exemplo complementar e na mesma direção refere-se aos limites de acompanhamento do desempenho familiar fora de sala de aula, por parte das famílias com mães de baixa escolaridade. Neste caso, a oferta de escolas de tempo integral não deve jamais almejar uma universalização imediata, sendo mais eficiente a provisão da escola de tempo integral para as famílias com mães de baixa escolaridade, sendo elas as mais pobres ou não.

Goldani (2004) também pergunta: "Qual família?" Esta questão é totalmente pertinente. Os arranjos domiciliares e familiares são diversos. Famílias com crianças não são exclusivamente as nucleares biparentais, que fazem parte do imaginário. Há, também, as famílias monoparentais, principalmente aquelas de responsabilidade feminina. Algumas crianças estão em famílias extensas, muitas das quais são, na realidade, compostas por mãe jovem e criança, vivendo com os pais da mãe.

A "diversidade e fluidez" dos arranjos familiares (na expressão de Goldani) dificultam a formulação de políticas para a família, que partam de pressupostos simplistas. Acrescenta-se, aos pontos mencionados por Goldani, o fato de que políticas focalizadas podem servir de incentivos nãointencionais a novos arranjos familiares, como se observa no debate norte-americano acerca do impacto de políticas de "welfare" sobre a gravidez na adolescência. Estes aspectos e complexidades não devem servir de barreira ao foco na família, entendida como a agregação de todos os arranjos possíveis, congregando, de forma conflituosa, uma ou mais gerações no seu interior. Questões de desigualdade de ativos (ou classe, ou estratificação social), de gênero e de raça são dimensões que perpassam estes arranjos. 
Neste sentido, faltou um maior detaIhamento das questões macro e micro de gênero, em que não só se destaca a saúde reprodutiva, mas também a sobremortalidade masculina dos jovens, bem como o hiato de gênero na educação (escolaridade feminina maior do que a masculina).

No caso dos jovens, faltou uma discussão sobre a transição para a vida adulta, em que a correlação entre decisões na esfera de escolaridade, mercado de trabalho, formação de um novo arranjo familiar, fecundidade e sexualidade é componente crucial. Os idosos são um caso à parte, tanto para os arranjos familiares quanto na questão do envelhecimento sem incapacidade e com autonomia. A questão racial é primordial na interação com os diferenciais observados nas outras dimensões, sendo importante tanto para a análise das carências de políticas públicas e no debate universalização versus focalização, quanto no caso de estratégias diferenciais de arranjos familiares, para jovens e idosos.

A despeito das limitações aqui apontadas, é possível concluir que a dinâmica demográfica brasileira, principalmente no que concerne à sua estrutura etária, oferece uma série de oportunidades e desafios para o planejamento do desenvolvimento humano no país nas próximas décadas.

\section{Referências bibliográficas}

ANDRADE, E. (Des)equilíbrio da previdência social brasileira - 1945-1997 (componentes econômico, demográfico e institucional. Tese de doutorado. Minas Gerais: Cedeplar/UFMG, 1999.

AZEVEDO, D. Brasileiros no exterior. Nota técnica, Consultoria Legislativa da Área XVIII, Congresso Nacional. Brasília, setembro, 2004.

\footnotetext{
BANCO MUNDIAL. Educação municipal no Brasil - recursos, incentivos e resultados. Departamento de Desenvolvimento Humano. Brasil: Unidade de Gerenciamento do País, dois volumes, janeiro de 2003 (Relatório n. 24413-BR).
}

Os efeitos de composição, dividendo demográfico e transferências intergeracionais são apenas exemplos de tópicos a serem perseguidos em estudos futuros, bem como em suas aplicações e formulações de políticas públicas.

Um ponto comum nestes três tópicos refere-se ao papel crucial conferido à educação na dinâmica futura. A análise sobre o efeito de composição mostrou que existe significativo aumento na escolaridade materna, processo este que favorece ao crescimento da demanda por escolaridade e à melhoria no desempenho escolar. Por outro lado, o debate sobre o dividendo demográfico mostrou que a redução na razão de dependência demográfica na infância, durante os anos 90, foi fundamental para que a política governamental de expansão da cobertura escolar fosse bem-sucedida. Além disso, o aumento futuro na escolaridade da PEA é motivo essencial para se evitar um declínio na razão de suporte.

Finalmente, se a seguridade social foi implantada anteriormente a um aumento no gasto público com educação, sua viabilidade futura num sistema de repartição dependerá de uma verdadeira revolução na política pública de educação, algo que é compatível com a hipótese de eficiência, mas, por enquanto, é só uma possibilidade.

BARRO, R. Are government bonds net wealth? Journal of Political Economy, 82(6), p. 1095-1117, 1974.

BAPTISTA, D.B.A. Idosos no município de São Paulo: expectativa de vida ativa e perfis multidimensionais de incapacidade a partir da SABE. Tese de mestrado. Minas Gerais: Cedeplar/UFMG, 2003.

BARROS, R.P. e CARVALHO, M. Desafios para a política social brasileira. Ipea, 2003 (Texto para discussão,TD 985).

BEAUDRY, P. e COLLARD, F. Recent technological and economic change among industrialized countries: Insights from population growth. Scandinavian Journal of Economics, 105(3), p. 441-463, 2003. 
BEAUDRY, P., COLLARD, F. e GREEN, D.A. Explaining productivity growth: the role of demographics. International Productivity Monitor, n.10, spring 2005.

BECKER, G. e TOMES, N. Human capital and the rise and fall of families. Journal of Labor Economics, 4, 1986.

BECKER, G. e MURPHY, K. The family and the state. Journal of Law and Economics, 31(1), p. 1-18, 1988.

BERQUÓ, E. Análise do ciclo vital visto da perspectiva do "quantum" e do "tempo" da fecundidade: estudo comparativo de contextos brasileiros. ENCONTRO NACIONAL DE ESTUDOS POPULACIONAIS, 2, 1980. Anais... Abep, 1980.

BERQUÓ, E. e CAVENAGHI, S. Mapeamento sócio-econômico e demográfico dos regimes de fecundidade no Brasil e sua variação entre 1991 e 2000. ENCONTRO NACIONAL DE ESTUDOS POPULACIONAIS, 14, Caxambu, MG, 2004. Anais... Abep, 2004.

BIRDSALL, N., KELLEY, A.C. e SINDING, S.W. (Eds.). Population matters: demographic change, economic growth, and poverty in the developing world. Oxford University Press, 2001.

BOLDRIN, M. e MONTES, A. The intergenerational state: Education and pensions. Federal Reserve Bank of Minneapolis. Research Department Staff Report 336, May 2004.

BOMMIER, A., LEE, R., MILLER, T. e ZUBER, $S$. Who wins and who loses? Public transfer accounts for US generations for 1850 to 2090. Trabalho apresentado na XXV CONFERÊNCIA INTERNACIONAL DE POPULAÇÃO DA UNIÃO INTERNACIONAL PARA OS ESTUDOS CIENTÍFICOS DE POPULAÇÃO (IUSSP), Sessão 24: Intergenerational relations in the context of population ageing. Tours, França, 18-23 de julho, 2005.

CARVALHO, J.A.M. O tamanho da população brasileira e sua distribuição etária: Uma visão prospectiva. ENCONTRO NACIONAL DE ESTUDOS POPULACIONAIS, 6, 1988. Anais... Abep, v. 1, 1988.
CARVALHO, J.A.M. O saldo dos fluxos migratórios internacionais do Brasil na década de 80 - uma tentativa de estimação". Revista Brasileira de Estudos de População, Campinas: Abep, v. 13, n.1, jan./jun., p. 3-14, 1996.

CARVALHO, J.A.M. e GARCIA, R.A. O envelhecimento da população brasileira: um enfoque demográfico. Cadernos de Saúde Pública. Rio de Janeiro, 19(3), maiojun., p. 725-733, 2003.

CARVALHO, J.A.M. Migrações internacionais do Brasil nas duas últimas décadas do século XX: algumas facetas de um processo complexo, amplamente desconhecido. SEMINÁRIO DE MIGRAÇÃO INTERNACIONAL - MINISTÉRIO DA PREVIDÊNCIA SOCIAL. Brasília, julho, 2004, no prelo.

FEYRER, J. Demographics and productivity. Dartmouth College, 2002, mimeo.

GOLDANI, A.M. Contratos intergeracionais e reconstrução do Estado de Bem-Estar. Por que se deve repensar essa relação para o Brasil? In: CAMARANO, A.A. (Org.). Os novos idosos brasileiros - muito além dos 60? Rio de Janeiro, Instituto de Pesquisa Econômica Aplicada - Ipea, cap. 7, setembro de 2004.

IBGE. Evolução da mortalidade, 2001. Disponível em: <http://www.ibge.gov.br/ home/estatistica/populacao/tabuadevida/ default_2001.shtm>. Acessado em 15 nov. 2004.

LOZANO-ASCENCIO, F. Remittance behaviour among latin american immigrants in the United States. Trabalho apresentado na XXV CONFERÊNCIA INTERNACIONAL DE POPULAÇÃO DA UNIÃO INTERNACIONAL PARA OS ESTUDOS CIENTÍFICOS DE POPULAÇÃO (IUSSP), Sessão 95: The demography of Latin America. Tours, França, 18-23 de julho, 2005.

MARTES, A.C.B. Empresários brasileiros em East Boston e Cambridge. FGV-Eaesp/ GVPesquisa, 2004 (Relatório de Pesquisa, 20).

MASON, A., LEE, R., TUNG, A-C., MUN, S.L. e MILLER, T. Population aging and 
intergenerational transfers: introducing aging into national accounts. Trabalho apresentado na XXV CONFERÊNCIA INTERNACIONAL DE POPULAÇÃO DA UNIÃO INTERNACIONAL PARA OS ESTUDOS CIENTÍFICOS DE POPULAÇÃO (IUSSP), Sessão 174: Economics of population ageing and population decline. Tours, França, 18-23 de julho, 2005.

MASON, A. Demographic transition and demographic dividends in developed and developing countries. UNITED NATIONS EXPERT GROUP MEETING ON SOCIAL AND ECONOMIC IMPLICATIONS OF CHANGING POPULATION AGE STRUCTURES. Mexico City, Population Division, 31 de agosto a 2 de setembro, 2005.

MIRANDA-RIBEIRO, P. Aula inaugural do ano letivo. Minas Gerais, Cedeplar/UFMG, 2004 (PowerPoint).

MULLIGAN, C.B. e SALA-I-MARTIN, X. Social security in theory and practice (I): facts and political theories. National Bureau of Economic Research (Working paper, 7119), 1999a. Disponível em: <http:// www.nber.org/papers/w7119>. Acessado em 15 ago. 2005.

MULLIGAN, C.B. e SALA-I-MARTIN, X. Social security in theory and practice (II): efficiency, theories, narrative theories, and implications for reform. National Bureau of Economic Research (Working paper, 7119), 1999b. Disponível em: <http:// www.nber.org/papers/w7119>. Acessado em 15 ago. 2005.

OLIVEIRA, J. e ALBUQUERQUE E LINS, F. Projeção da população do Brasil por sexo e idade para o período 1980-2050 Revisão 2004. Rio de Janeiro, IBGE, outubro 2004.

POGUE, T.F. e SGONTZ, L.G. Social security and investment in human capital. National Tax Journal, 30(2), June, 1977, apud, C. MULLIGAN e X. SALA-I-MARTIN, 1999b.

PRESTON, S.H. Children and the elderly: divergent paths for America's dependents. Demography, 21(4), p. 435-457, 1984.
PRSKAWETZ, A. e FENT, T. Workforce ageing and economic productivity: the role of supply and demand of labour. An application to Austria. Trabalho apresentado na XXV CONFERÊNCIA INTERNACIONAL DE POPULAÇÃO DA UNIÃO INTERNACIONAL PARA OS ESTUDOS CIENTÍFICOS DE POPULAÇÃO (IUSSP), Sessão 174: Economics of population ageing and population decline. Tours, França, 18-23 de julho, 2005.

RIANI, J.L.R. Impactos da estrutura etária em indicadores de educação no Brasil. Dissertação de mestrado. Minas Gerais: Cedeplar/UFMG, 2001.

RIANI, J.L.R. Os determinantes do resultado educacional no Brasil: família, perfil escolar do município e dividendo demográfico numa abordagem hierárquica e espacial. Tese de doutorado. Minas Gerais: Cedeplar/UFMG, 2005.

SILVA, V.C., MIRANDA-RIBEIRO, A. e RIOSNETO, E.L.G. A period decomposition of fertility decline in Brazil: pure fertility index, tempo, and parity composition effects. Trabalho apresentado na XXV CONFERÊNCIA INTERNACIONAL DE POPULAÇÃO DA UNIÃO INTERNACIONAL PARA OS ESTUDOS CIENTÍFICOS DE POPULAÇÃO (IUSSP), Sessão 63: Demographic issues in developing countries having low fertility. Tours, França, 18-23 de julho, 2005.

SIMÃO, A.B., MIRANDA-RIBEIRO, P., CAETANO, A.J. e CÉSAR, C.C. Comparando as idades à primeira relação sexual, à primeira união e ao nascimento do primeiro filho de duas coortes de mulheres brancas e negras em Belo Horizonte: evidências quantitativas. Revista Brasileira de Estudos Populacionais, 2005, no prelo.

SOARES, R.R. Mortality reductions, education attainment, and fertility choice. American Economic Review, 95 (3), June, p. 580-601, 2005.

SOCHACZEWSKI, A.C. Finanças públicas no século $X X$. Estatísticas do Século $X X$. Rio de Janeiro, IBGE. Centro de Documentação e Disseminação de Informações, 2003. 
TABELLINI,G. A positive theoryof social security. IGIER, Milano, Italy, February 1992, apud C. MULLIGAN e X. SALA-I-MARTIN, 1999a.

TURRA, C.M. Contabilidade das gerações: riqueza, sistema de transferências e conseqüências de mudanças no padrão demográfico. Dissertação de mestrado. Minas Gerais: Cedeplar/UFMG, 2000.

TURRA, C. e QUEIROZ, B. Intergenerational transfers and socioeconomic inequality in Brazil: A first look. Taller sobre Transformaciones Demograficas, Transferencias Intergeneracionales y Proteccion Social en America Latina.
Santiago, Chile, Celade, 6 a 7 de julho 2005a.

TURRA, C. e QUEIROZ, B. Before it's too late: demographic transition, labor supply, and social security problems in Brazil. UNITED NATIONS EXPERT GROUP MEETING ON SOCIAL AND ECONOMIC IMPLICATIONS OF CHANGING POPULATION AGE STRUCTURES. Mexico City, Population Division, 31 de agosto a 2 de setembro, 2005b.

TURRA, C. e QUEIROZ, B. Transferências intergeracionais: uma análise internacional.

Revista Brasileira de Estudos de População, 2005, no prelo.

\section{Abstract}

New issues in demographic analysis: the case of Brazil

This article begins with a review of the three components of demography, stressing the decline in fertility, with the possibility of the country's reaching a level of below replacement fertility. Studies on new trends in Brazilian emigration are considered relevant for future research. The demography of compositional effects is discussed in terms of an exercise with fertility differentials according to the mothers' education. The exercise shows that the historical improvement in mothers' education has offset the possible adverse effects of high fertility among mothers with low levels of education. The demographic dividend is discussed both conceptually and empirically, and directions for future studies are indicated. Finally, the article presents a conceptual discussion on intergenerational transfers, with emphasis on public expenditures and social policy. New studies being developed on this topic are also mentioned.

Key words: Below-replacement fertility. Demographic dividend. Intergenerational transfers. Education. Social security. 